\title{
A NARROW GROUP OF MONOPHYLETIC TULASNELLA (TULASNELLACEAE) SYMBIONT LINEAGES ARE ASSOCIATED With MULTIPLE SPECIES OF CHILOGLOTTIS (ORCHIDACEAE): IMPLICATIONS FOR ORCHID DIVERSITY ${ }^{1}$
}

\author{
Sean A. Roche, Richard J. Carter, Rod Peakall, Leon M. Smith, \\ Michael R. Whitehead, and Celeste C. Linde ${ }^{2}$
}

Evolution, Ecology and Genetics, Research School of Biology, 116 Daley Road, The Australian National University, Canberra, ACT 0200, Australia

- Premise of the study: The Orchidaceae is characterized by exceptional species diversity. Obligate orchid mycorrhizae are predicted to determine orchid distributions, and highly specific relationships between orchids and fungi may drive orchid diversification. In this study, mycorrhizal diversity was examined in the terrestrial, photosynthetic orchid genus Chiloglottis to test the hypothesis of mycorrhizal-mediated diversification in the genus Chiloglottis. This orchid genus secures pollination by sexual deception, an obligate and highly specific pollination strategy. Here we asked whether the obligate orchid-fungal interactions are also specific.

- Methods: Two sequenced loci, the internal transcribed spacer region (ITS) and mitochondrial large subunit (mtLSU), were used to identify fungal isolates and assess fungal species diversity. Symbiotic germination of two species Chiloglottis aff. jeanesii and $C$. valida were used to assess germination potential of isolates and confirm mycorrhizal association.

- Key results: Phylogenetic analyses revealed that six representative Chiloglottis species spanning a broad survey of the genus were all associated with a narrow group of monophyletic Tulasnella fungal lineages.

- Conclusions: The Chiloglottis-Tulasnella interaction appears to be the first known case of such a narrow symbiont association across a broadly surveyed orchid genus. It appears that the specific pollination system of Chiloglottis, rather than specific orchid-fungal interactions has been the key driving force in the diversification of the genus. These findings also indicate that plant groups with highly specific mycorrhizal partners can have a widespread distribution.

Key words: ectomycorrhizae; Chiloglottis; ITS; mtLSU; molecular phylogeny; orchid mycorrhizal fungi; Orchidaceae; Tulasnellaceae.

Coevolution involving intimate interactions between two different groups of organisms is proposed to be a key driving force in speciation, especially when relationships display a high level of specificity such as host-parasite relationships and specific pollination systems (Barrett, 1986; Thompson, 1986; Weiblen, 2004). The Orchidaceae represents one of the most diverse plant families, and it has been proposed that this diversity could, in part, be driven by the often-specific interactions with animal pollinators (Peakall, 2007; Scopece et al., 2007; Peakall et al., 2010). It has been predicted that this diversity has been strongly influenced by the unique features of orchid reproduction and the associated specific interactions with insect pollinators (Cozzolino and Widmer, 2005). The below-ground orchid interactions involving symbiotic fungi, which in some cases demonstrate high levels of specificity, may have also played a key role in speciation within certain orchid groups (Taylor et al., 2003; Otero and Flanagan, 2006; Waterman and Bidartondo, 2008). Documenting the underlying patterns of orchid-fungal

\footnotetext{
1 Manuscript received 8 February 2010; revision accepted 19 May 2010.

The authors thank Prof. Kingsley Dixon (Director of Science, Kings Park and Botanic Gardens, Perth) for advice on seed germination classification.

2 Author for correspondence (e-mail: celeste.linde@anu.edu.au)
}

doi:10.3732/ajb.1000049 interactions is therefore critical for a more complete understanding of the evolution of orchid diversity.

The minute, wind-dispersed seeds of orchids are undifferentiated and do not store sufficient nutrition for unaided development of the embryo (Arditti, 1992). Thus, all orchids require mycorrhizal fungi, at least for germination and early seedling phases (Warcup, 1990; Arditti, 1992). During the early seedling phase, they may be considered parasitic on their fungal symbionts because nutrients are directed exclusively to the plant (Hadley, 1970; Waterman and Bidartondo, 2008; Rasmussen and Rasmussen, 2009). Even as photosynthetic adults, many terrestrial species may still rely on fungal-mediated transfer of nutrients and carbon, especially in forests where light can be limited (Bidartondo, 2005; Cameron et al., 2006). Whether this relationship remains parasitic in later growth stages may vary according to the photosynthetic ability of the orchid (Cameron et al., 2006, 2009).

Most orchids are photosynthetic, and there is no evidence that they obtain a majority of their energy from the fungi, except at the early stages in development following germination (Taylor, 2004; Rasmussen and Rasmussen, 2009). However, mutualistic orchid-fungal associations have been confirmed by radioactively labeled carbon and phosphorous studies, where bidirectional flow of carbon has been observed between fungal symbionts and the orchid Goodyera repens (Cameron et al., 2006, 2007). More species need to be investigated to determine whether this bidirectional nutrient flow is a general pattern in 
the trophic interactions between green orchids and fungi. If so, an association of mycorrhizae with orchids may provide a longterm benefit to both partners, and the exchange of limiting compounds may broaden the ecological range of either partner and overcome physiological stresses (Arditti, 1992; Bidartondo, 2005). Interactions between photosynthetic orchids and their mycorrhizae may therefore represent a complex and dynamic relationship between parasitism and mutualism, which can change across the life cycle of the host/symbiont and in response to changes in environmental conditions (Harley and Smith, 1983; Arditti, 1992; Hynson et al., 2009).

Highly specific relationships with obligate fungal partners have been proposed as a possible driving force in the diversification of some photosynthetic orchids (Otero and Flanagan, 2006; Shefferson et al., 2007), nonphotosynthetic orchids (Taylor et al., 2003), and members of the Monotropoideae (Bidartondo and Bruns, 2001). However, the occurrence of species-specific orchid-fungal relationships is unlikely to be a consequence of cospeciation (reciprocal speciation as a consequence of the interaction) (Thompson, 1986; Taylor et al., 2003) because orchid mycorrhizae are not dependent on orchids for reproduction and dispersal and can survive as either saprophytes (e.g., Tulasnella species [Roberts, 1999]) or parasites (e.g., Armillaria mellea [Rasmussen, 2002]). One proposed mechanism for fungaldriven speciation is analogous to "mixed-process coevolution" (Thompson, 1986), by which changes in specificity of orchid species for compatible fungi are predicted to result in reproductive isolation among plant hosts with different specific fungi. However, in their recent review, Waterman and Bidartondo (2008) stated that a direct link between mycorrhizal specificity and reproductive isolation of the plant host is hard to envision.

A second mechanism for fungal driven speciation has been suggested in which mycorrhizal specialization has indirect consequences for the diversity of host species by determining orchid distributions (Otero et al., 2004; Otero and Flanagan, 2006; Waterman and Bidartondo, 2008). Under this scenario, it is postulated that the often widespread but patchy distributions of orchid populations are an indirect consequence of narrow mycorrhizal associations and patchy fungal distributions. If gene flow between such populations is limited, as evident for some epiphytic species (Tremblay and Ackerman, 2001), a combination of drift and episodic selection may drive speciation (Otero et al., 2004; Waterman and Bidartondo, 2008).

The first step in testing whether fungal interactions play a role in orchid speciation is to investigate whether there is fungal specificity between orchids and their obligate mycorrhizal partners. Furthermore, teasing out the role of fungi in speciation is best done in those systems for which both fungal and pollinator interactions are well understood (Waterman and Bidartondo, 2008). In this study, we targeted the much-studied photosynthetic, Australian, terrestrial orchid genus Chiloglottis, a genus that uses the unusual pollination strategy of sexual deception, attracting male pollinators by mimicry of their sex pheromones (Schiestl et al., 2003; Franke et al., 2009). The pollination strategy of sexual deception is particularly well developed within Australian sexually deceptive orchids with more than 150 species across multiple genera involved (Peakall, 1990; Peakall and Beattie, 1996; Bower and Brown, 2009; Phillips et al., 2009). Chiloglottis is one of the largest and most widespread Australian sexually deceptive orchid genera with 23 described species and likely more than 30 species when cryptic taxa are taken into account (Peakall et al., 2002; Bower, 2006; Bower and Brown, 2009).
As is generally the case for sexually deceptive orchids, pollinator interactions with Chiloglottis are highly specific; a one to one relationship between orchid and pollinator is typical for a given site (Bower, 1996, 2006; Bower and Brown, 2009), although some pollinator sharing the edge of a species range is known (Peakall et al., 2002). The discovery of the specific chemicals representing a new class of compounds used by Chiloglottis orchids to lure their male pollinators (Schiestl et al., 2003; Franke et al., 2009; Peakall et al., 2010) confirms that pollinator specificity has a strong chemical basis. It has been hypothesized that changes in floral chemistry that enable pollinator switching, combined with subsequent pollinator-mediated selection, have played a key role in the evolution and diversification of Chiloglottis (Mant et al., 2002, 2005; Peakall et al., 2010).

Despite this extensive work on pollinator specificity, it is important that the potential role of below-ground interactions - the obligate interaction between orchid and fungal mycorrhizal associates (Waterman and Bidartondo, 2008) - is not neglected in studies of orchid diversification. Therefore, the overarching question we ask in this study is what role, if any, might specific fungal relationships have played in the diversification of the orchid genus Chiloglottis? We attempted to answer this by addressing four specific questions: (1) Which fungi and how many fungal species are involved in partnership with six Chiloglottis species strategically chosen to represent the phylogenetic breadth across the genus? (2) What is the germination potential of the fungal isolates associated with Chiloglottis species? (3) What are the phylogenetic relationships of the fungal symbionts? (4) Finally, what are the implications of our findings for the current hypotheses on the diversification of Chiloglottis and for other orchids more generally?

\section{MATERIALS AND METHODS}

Sample collection-All members of the genus Chiloglottis are small terrestrial herbs that grow as colonies in moist, sheltered locations in the open forests of the coast and the Great Dividing Range of eastern Australia. Several species are also found in Tasmania. Plants are characterized by two opposite leaves that are usually prostrate on the soil surface. Single flowers are inconspicuous and dull-colored on a stem 3-15 cm high. All species go through a dormancy phase over either summer or winter, depending on the flowering time of the species. Clonal colonies are formed as a result of vegetative reproduction when more than one daughter tuber is produced in a season (Peakall et al., 1997).

For this study, six species were selected to span the phenological and phylogenetic diversity across Chiloglottis s.l. as revealed by phylogenetic analysis (Mant et al., 2002; Peakall et al., 2010). Note that in some recent taxonomic treatments (e.g., Jones, 2006), Chiloglottis has been split into three genera. However, for nomenclatural continuity among the many publications on this group and because these taxonomic changes are not universally accepted, we retain the genus name Chiloglottis. Three species represented the autumn-flowering Reflexa group: $C$. diphylla R.Br., C. reflexa (Labill.) Druce, C. seminuda D.L. Jones. One species represented the spring-flowering Formicifera group: $C$. trapeziformis Fitzg. Two species represented the spring/summer-flowering Valida group: $C$. valida D.L. Jones and $C$. aff. jeanesii. Adult Chiloglottis plants were collected from field sites in New South Wales (NSW) and the Australian Capital Territory (ACT), Australia (Table 1, Fig. 1). Voucher specimens of the fungi are stored in the culture collection of the author's laboratory at the Australian National University, Canberra (ANU; see Appendix 1).

The species selected are broadly sympatric in at least parts of their range and at some sites multiple species may co-occur. For example, at least two species each within the Reflexa and Valida groups may co-occur. Furthermore, both groups may be found at the one site, for example $C$. valida and $C$. aff. jeanesi frequently co-occur and flower together in October.

Fungal isolation-Isolations were conducted within 1 to $7 \mathrm{~d}$ after the plants were collected from the field. Peloton-rich zones at the collar region of the tuber 
TABLE 1. Chiloglottis species and collection details from which mycorrhizal pelotons were cultivated: Colony $=$ plant colony code; Abbrev. $=$ site name abbreviation; No. of plants = number of plants from which pelotons were successfully germinated; No. of mtLSU haplyptes = number of mtLSU haplotypes obtained from/number of fungal isolates sequenced; No. of ITS clonal types = number of ITS clonal types obtained from/number of fungal isolates sequenced; * = indicates fungal DNA amplified from plant tissue for Tulasnella isolates; ACT = Australian Capital Territory; NSW = New South Wales

\begin{tabular}{|c|c|c|c|c|c|c|c|c|c|}
\hline Colony & Site name & Abbrev. & $\begin{array}{l}\text { Chiloglottis } \\
\text { species }\end{array}$ & GPS & $\begin{array}{l}\text { Collection } \\
\text { date }\end{array}$ & Region & $\begin{array}{l}\text { No. of } \\
\text { plants }\end{array}$ & $\begin{array}{c}\text { No. of } \\
\text { mtLSU } \\
\text { haplotypes }\end{array}$ & $\begin{array}{l}\text { No. of ITS } \\
\text { haplotypes }\end{array}$ \\
\hline 0505 & Bilpin Park Site 1 & BP1 & C. diphylla & $\begin{array}{l}\text { S33.51549 } \\
\text { E150.48861 }\end{array}$ & $31 / 3 / 07$ & Blue Mtns., Bells Line Rd, NSW & 1 & $1 / 2$ & $1 / 1$ \\
\hline 07054 & Bilpin Park Site 1 & BP1 & C. diphylla & $\begin{array}{l}\text { S33.51549 } \\
\text { E150.48861 }\end{array}$ & $31 / 3 / 07$ & Blue Mtns., Bells Line Rd, NSW & 3 & $2 / 3$ & - \\
\hline 07053 & Bilpin Park Site 2 & BP2 & C. diphylla & $\begin{array}{l}\text { S33.49537 } \\
\text { E150.51754 }\end{array}$ & $31 / 3 / 07$ & Blue Mtns., Bells Line Rd., NSW & 1 & $1 / 1$ & - \\
\hline 07050 & Kurrajong Heights & $\mathrm{KH}$ & C. diphylla & $\begin{array}{l}\text { S33.54073 } \\
\text { E150.63308 }\end{array}$ & $31 / 3 / 07$ & Blue Mtns., Bells Line Rd., NSW & 1 & $1 / 1$ & - \\
\hline 07048 & Kurrajong Heights & $\mathrm{KH}$ & C. diphylla & $\begin{array}{l}\text { S33.54073 } \\
\text { E150.63308 }\end{array}$ & $31 / 3 / 07$ & Blue Mtns., Bells Line Rd., NSW & 1 & $1 / 1$ & - \\
\hline 07071 & $\begin{array}{l}\text { Mt. Irvine Rd. Mt. } \\
\text { Wilson }\end{array}$ & MI & C. reflexa & $\begin{array}{l}\text { S33.49979 } \\
\text { E150.41446 }\end{array}$ & $1 / 4 / 07$ & Mt Wilson, Blue Mtns., NSW & 1 & $1 / 1$ & - \\
\hline 07072 & $\begin{array}{l}\text { Mt. Irvine Rd. Mt. } \\
\text { Wilson }\end{array}$ & MI & C. reflexa & $\begin{array}{l}\text { S33.49979 } \\
\text { E150.41446 }\end{array}$ & $1 / 4 / 07$ & Mt Wilson, Blue Mtns., NSW & 1 & $1 / 2$ & - \\
\hline 07061 & $\begin{array}{l}\text { Wynnes Lookout, Mt } \\
\text { Wilson }\end{array}$ & WL & C. reflexa & $\begin{array}{l}\text { S33.52118 } \\
\text { E150.37075 }\end{array}$ & $1 / 4 / 07$ & Mt Wilson, Blue Mtns., NSW & 2 & $1 / 3$ & $1 / 1$ \\
\hline $07033-45$ & Hanging Rock Rd. & HR & C. seminuda & $\begin{array}{l}\text { S34.62842 } \\
\text { E150.19429 }\end{array}$ & $31 / 3 / 07$ & Penrose Forest, Exeter, NSW & 1 & $1 / 1$ & $1 / 1$ \\
\hline 07033 & Hanging Rock Rd. & HR & C. seminuda & $\begin{array}{l}\text { S34.62842 } \\
\text { E150.19429 }\end{array}$ & $31 / 3 / 07$ & Penrose Forest, Exeter, NSW & 4 & $1 / 8$ & $2 / 2$ \\
\hline SRBG01 & $\begin{array}{c}\text { Australian National } \\
\text { Botanic Gardens }\end{array}$ & ANBG & C. trapeziformis & $\begin{array}{l}\text { S35.27514 } \\
\text { E149.10973 }\end{array}$ & $5 / 9 / 07$ & Black Mountain, ACT & 2 & $1 / 5$ & $3 / 3$ \\
\hline SRBG03 & $\begin{array}{c}\text { Australian National } \\
\text { Botanic Gardens }\end{array}$ & ANBG & C. trapeziformis & $\begin{array}{l}\text { S35.27514 } \\
\text { E149.10973 }\end{array}$ & $18 / 9 / 08$ & Black Mountain, ACT & 4 & - & $6 / 9 *$ \\
\hline SRBM01 & Black Mountain & $\mathrm{BM}$ & C. trapeziformis & $\begin{array}{l}\text { S35.27496 } \\
\text { E149.09765 }\end{array}$ & 18/9/08 & Black Mountain, ACT & 1 & - & $2 / 2 *$ \\
\hline CM07 & Black Mountain & $\mathrm{BM}$ & C. trapeziformis & $\begin{array}{l}\text { S35.27496 } \\
\text { E149.09765 }\end{array}$ & 29/12/06 & Black Mountain, ACT & 2 & $1 / 4$ & $2 / 4$ \\
\hline СР0835 & Boyd River fire trail & BRFT & C. aff. jeanesii & $\begin{array}{l}\text { S33.94092 } \\
\text { E150.05520 }\end{array}$ & 29/10/07 & Kanangra Boyd Natl. Park, NSW & 4 & $2 / 8$ & $11 / 12$ \\
\hline 06082 & Lowden Rd. & LR & C. aff. jeanesii & $\begin{array}{l}\text { S35.50567 } \\
\text { E149.53510 }\end{array}$ & $4 / 10 / 06$ & Tallaganda State Forest, NSW & 1 & $1 / 2$ & $3 / 4$ \\
\hline CV0836 & Boyd River fire trail & BRFT & C. valida & $\begin{array}{l}\text { S33.94092 } \\
\text { E150.05520 }\end{array}$ & 29/10/07 & Kanangra Boyd Natl. Park, NSW & 2 & $1 / 2$ & $1 / 1$ \\
\hline CV0627 & Lowden Rd. & LR & C. valida & $\begin{array}{l}\text { S35.50567 } \\
\text { E149.53510 }\end{array}$ & $4 / 10 / 06$ & Tallaganda State Forest, NSW & 1 & $1 / 2$ & $1 / 1$ \\
\hline Total & & 10 & 6 & & & & 33 & 3 & 35 \\
\hline
\end{tabular}

and rhizome were rinsed successively with sterilized distilled water in three petri dishes to remove surface contaminants. Rinsed tissue was then macerated in sterile distilled water containing $50 \mathrm{mg} / \mathrm{mL}$ streptomycin sulfate. Single pelotons as well as small plant tissue sections containing pelotons were transferred to fungal isolation media (FIM) agar plates (Clements and Ellyard, 1979) and incubated at room temperature in the dark. After $1 \mathrm{wk}$, germinating pelotons were transferred to new FIM plates. Even though tubers were not surface-sterilized before peloton extraction, only 5\% of isolations were deemed contaminated by obvious contaminants such as Penicillium. All colonies were hyphal-tipped after three weeks to ensure single colonies. Cultures were stored on sterilized wheat and FIM agar slants covered with mineral oil at $5^{\circ} \mathrm{C}$.

DNA extraction and sequence analysis-For DNA extraction, fungal isolates were grown in FIM (Clements and Ellyard, 1979) broth in petri dishes. Petri dishes were inoculated with 10-20,1 mm agar blocks cut from colony edges of isolates grown on FIM agar and incubated at room temperature in the dark for 2 wk. In cases where isolates did not grow in FIM broth, DNA was extracted directly from agar cultures. The DNA extraction followed a protocol for lyophilized mycelium, using cetyltrimethylammonium bromide (CTAB) (Lee and Taylor, 1990).

To investigate the presence of fungal species that could not be cultured in vitro, we extracted DNA from $C$. trapeziformis tissue $(N=4$ from site ANBG,
$N=1$ from BM) (Table 1) using Qiagen DNeasy Plant mini kit (Amersham Biosciences, Hilden, Germany) according to the manufacturer's instructions. Soil contamination was minimized by cleaning and sectioning plants as described before, leaving peloton-dense sections for DNA extraction.

A range of primer combinations were initially assessed to amplify mycorrhizal nuclear and mitochondrial ribosomal DNA (rDNA). The nuclear rDNA loci, which included the internal transcribed spacer region (ITS), were initially amplified using universal primers ITS1 and ITS4 (White et al., 1990). ITS primers specifically designed to amplify certain groups of orchid mycorrhizae included genus-specific primers CeTh1 and CeTh4 (Porras-Alfaro and Bayman, 2007) for Ceratobasidium and Thanatephorus, ITS1OF and ITS4OF (Taylor and McCormick, 2008), as well as Tulasnella-specific ITS1 and ITS4tul (Taylor, 1997) and Tul1 and Tul4 (Porras-Alfaro and Bayman, 2007). For the mitochondrial large subunit, primer combinations ML7 and ML8 (White et al., 1990), as well as MLin3 (Bruns et al., 1998) and ML6 (White et al., 1990) were tested. Each $20-\mu \mathrm{L}$ PCR reaction contained $2 \mu \mathrm{L}$ PCR buffer (Scientifix, Melbourne, Australia); $25 \mathrm{mM} \mathrm{MgCl}, 0.2 \mathrm{mM}$ of each dNTP, 5 pmol of each primer; 0.5 U Taq polymerase (Scientifix) and 20-100 ng template DNA.

The following thermal cycling parameters were used in an Eppendorf Mastercycler (Hamburg, Germany) for the loci that amplified consistently, i.e., ITS1-4-tul, ITS1OF-ITS4OF, and MLIN3-ML6: initial denaturing for $2 \mathrm{~min}$ at $95^{\circ} \mathrm{C}$; followed by 35 cycles of denaturation for $1 \mathrm{~min}$ at $95^{\circ} \mathrm{C}$, annealing for $1 \mathrm{~min}$ at $55^{\circ} \mathrm{C}$, elongation for $1 \mathrm{~min}$ at $72^{\circ} \mathrm{C}$; and a final extension for $10 \mathrm{~min}$ at 


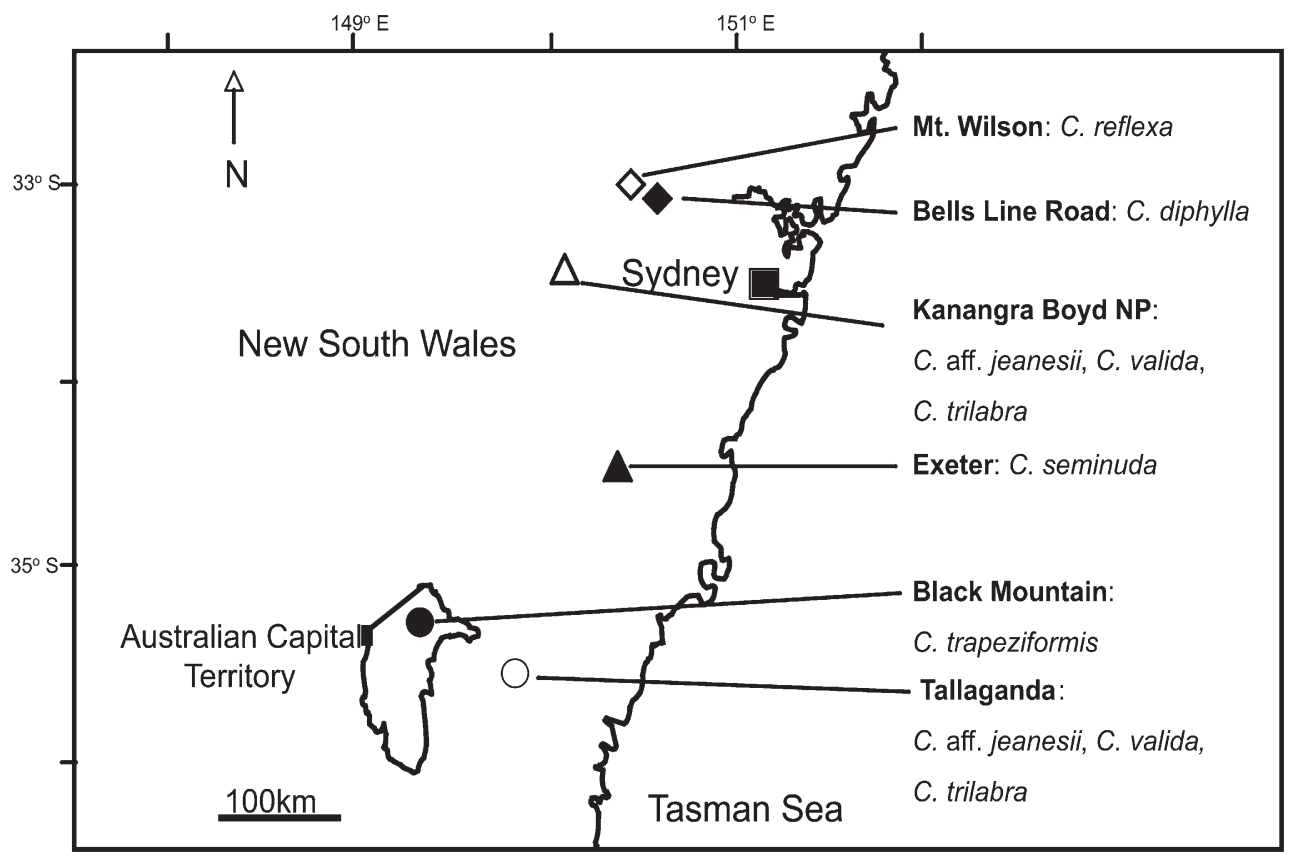

Fig. 1. Collection regions of Chiloglottis species from New South Wales (NSW) and the Australian Capital Territory (ACT), Australia, for mycorrhizal isolations.

$72^{\circ} \mathrm{C}$. Amplification products were electrophoresed on $1 \%$ agarose gels to verify the amplification of a single fragment of the appropriate length.

Because the ITS is a multicopy gene region and multiple copies were observed in the sequencing analysis, PCR products were cloned using pGem-T Easy Vector kit (Promega, Wisconsin, USA) according to the manufacturer's instructions. A list of isolates cloned in this study is provided in Table 2. Five white colonies per isolate were picked and cultured overnight in $E$. coli freezing medium [4.4\% glycerol, 8.21 g K $\mathrm{HPO}_{4} / \mathrm{L}, 1.80 \mathrm{~g} \mathrm{KH}_{2} \mathrm{PO}_{4} / \mathrm{L} ; 0.50 \mathrm{~g} \mathrm{Na}_{3}$ citrate /L; $0.10 \mathrm{~g} \mathrm{MgSO}_{4} \cdot 7 \mathrm{H}_{2} \mathrm{O} / \mathrm{L}, 0.90 \mathrm{~g}\left(\mathrm{NH}_{4}\right)_{2} \mathrm{SO}_{4} / \mathrm{L} ; 100 \mathrm{mg}$ ampicillin/L] to grow ample quantities for PCR. Colony PCR was carried out using $2-\mu \mathrm{L}$ cell suspension as template and SP6 and T7 promoter primers in $20-\mu \mathrm{L}$ reactions.

The PCR products were purified of inhibitory PCR reagents using Promega Wizard SV gel and PCR Clean-up System and ExoSAP-IT (GE Healthcare, Piscataway, New Jersey, USA) according to the manufacturer's instructions. Extension products were purified using an ethanol/EDTA/sodium acetate precipitation protocol according to the BigDye Terminator v3.1 sequencing kit instructions (Applied Biosystems, Foster City, California, USA). Products were sequenced bidirectionally with ABI PRISM BigDye Terminator v3.1 sequencing kit (Applied Biosystems) on an ABI-3100 automated sequencer. Sequences were edited using the program Sequencher v. 4.8 (GeneCodes, Ann Arbor Michigan, USA) to correct for base read ambiguities. BLAST searches were conducted on all obtained sequences to establish the closest relatives represented in the GenBank database.

Phylogenetic analysis-BLAST searches were conducted on the consensus sequences of the obtained mtLSU and ITS data set (http://www.ncbi.nlm.nih gov/BLAST), and GenBank sequences of the top BLAST hits were downloaded and included in the alignment. The multiple sequence alignment was conducted using an anchored multiple alignment with the program DIALIGN (Morgenstern et al., 2006). The alignment was manually adjusted using the program SE-AL v2.0a11 (Rambaut, 1996). Because of rapid evolution in the ITS, alignments were conducted with only highly similar sequences from GenBank. In the ITS alignment, none of the regions were excluded; highly variable regions in the outgroups that shared very little sequence in common with the ingroup were assumed to be either an insertion or a deletion and were offset. These indels contained very little information; therefore, indel coding was not applied.

Phylogenies were estimated with a maximum likelihood analysis using the program RAxML 7.0.4 (Stamatakis et al., 2008) as implemented at the Cyberinfrastructure for Phylogenetic Research (CIPRES) web portal 1.0 (http://www. phylo.org/sub_sections/portal) and Bayesian inference using the program MrBayes 3.1.2 (Ronquist and Huelsenbeck, 2003). A GTR+G model was used for all analyses because all other models are nested inside this model. Support for nodes was assessed for ML trees using nonparametric bootstrapping in RAxML (Stamatakis et al., 2008) and with Bayesian posterior probabilities (PP). The default parameters were used for both methods, with convergence and burn-in assessed according to the authors' recommendations (Ronquist and Huelsenbeck, 2003; Stamatakis et al., 2008).

The null hypothesis of no association between ITS haplotypes and orchid species $C$. trapeziformis and $C$. aff. jeanesii was tested with a contingency $\chi^{2}$ test (Everitt, 1977).

Orchid germination trials - To demonstrate germination potential of isolated fungi, we used three isolates for germination trials on seed pods of $C$. aff. jeanesii $(N=6)$ and $C$. valida $(N=4)$ collected from Kanangra Boyd National Park, NSW, Australia. Fungal isolates used in germination trials were 07061. III.7 from C. reflexa (Wynnes Lookout), CV0627.II.2 (Lowden Rd.) from $C$. valida, and 06082.II.1 from $C$. aff. jeanesii (Lowden Rd.).

Before plating out the seed for symbiotic germination, we assessed the percentage of testa with embryos using carmine acetate staining. All seed batches used for seed germination trials contained seed with a high presence of embryos ( $80 \%$ or higher).

To control for microbial contamination and enhance diffusion of water through removal of suberin, sodium hypochlorite solution was used to surfacesterilize seed. Seed from pods were mixed by inversion with $1 \mathrm{~mL}$ of a $1 \%$ $\mathrm{NaOCl}$ solution in $1.5 \mathrm{~mL}$ Eppendorf tubes for $10 \mathrm{~s}$. After soaking the seeds in the sterilizing solution for four minutes with inversion, seeds were centrifuged at $13000 \times \mathrm{g}$, for three minutes and the supernatant removed. This process was repeated three times. Seed was left to incubate overnight in the last rinse before the rinse solution was removed by centrifugation. Sterile distilled water $(1.2 \mathrm{~mL})$ was added to the seed, and aliquots of $400 \mu \mathrm{L}$ of seed suspended in solution were transferred to fungal oatmeal agar (OMA) (Clements and Ellyard, 1979). Two negative control plates were used for each seed treatment, which did not contain any fungal isolates. One plate was used for each fungal-seedpod treatment. Plates were incubated at $22^{\circ} \mathrm{C}$ in the dark to assist seed germination.

After 6 mo, total seed numbers were counted on every OMA plate. Only seeds that contained an intact embryo were included in the total seed counts. Seeds that developed into protocorms with leaves were considered germinated (stage 4: enlargement of protocorm with first green leaf and stage 5: seedling with green leaf and initiation of dropper) (Ramsay et al., 1986) (Fig. 2). Percentage seed germinated was calculated by dividing the number of stage 4 and stage 5 seeds by the total number of seeds per plate. A contingency $\chi^{2}$ test 
TABLE 2. Tulasnella isolates and their ITS and mtLSU haplotype as associated with six Chiloglottis species collected from sites in New South Wales and the Australian Capital Territory, Australia. Roman numerals of isolates refer to individual plants from which fungi were collected, followed by isolate number, then ITS clone number where applicable: $-=$ no sequence available; $\mathbf{m}=$ fungal sequences amplified from plant tissue; $*=$ NonTulasnella sequence

\begin{tabular}{|c|c|c|c|c|c|c|c|c|c|}
\hline Isolate & $\begin{array}{c}\text { Chiloglottis } \\
\text { species }\end{array}$ & Site & $\begin{array}{c}\text { ITS } \\
\text { haplotype no. }\end{array}$ & $\begin{array}{c}\text { mtLSU } \\
\text { haplotype } \\
\text { no. }\end{array}$ & Isolate & $\begin{array}{c}\text { Chiloglottis } \\
\text { species }\end{array}$ & Site & $\begin{array}{c}\text { ITS } \\
\text { haplotype no. }\end{array}$ & $\begin{array}{c}\text { mtLSU } \\
\text { haplotype } \\
\text { no. }\end{array}$ \\
\hline 06082.I.1.1 & C. aff. jeanesii & LR & 21 & 2 & 07033.II.3 & C. seminuda & HR & - & 2 \\
\hline 06082.I.1.2 & C. aff. jeanesii & LR & 22 & - & 07033.III.1 & C. seminuda & HR & - & 2 \\
\hline 06082.I.1.3 & C. aff. jeanesii & LR & 22 & - & 07033-45.I.2 & C. seminuda & HR & 19 & 2 \\
\hline 06082.I.3 & C. aff. jeanesii & LR & 1 & 2 & 07033.IV.1 & C. seminuda & HR & - & 2 \\
\hline CP0835.I.1.1 & C. aff. jeanesii & BRFT & 33 & 3 & 07033.IV.2 & C. seminuda & HR & - & 2 \\
\hline CP0835.I.1.2 & C. aff. jeanesii & BRFT & 28 & - & CM07.I.2 & C. trapeziformis & BM & - & 2 \\
\hline CP0835.I.1.3 & C. aff. jeanesii & BRFT & 28 & - & CM07.I.5 & C. trapeziformis & $\mathrm{BM}$ & 15 & 2 \\
\hline CP0835.I.2 & C. aff. jeanesii & BRFT & - & 3 & CM07.I.9 & C. trapeziformis & $\mathrm{BM}$ & - & 2 \\
\hline CP0835.III.1.1 & C. aff. jeanesii & BRFT & 33 & 3 & CM07.I.10 & C. trapeziformis & BM & 18 & 2 \\
\hline CP0835.III.1.3 & C. aff. jeanesii & BRFT & 27 & 3 & CM07.II.1.1 & C. trapeziformis & $\mathrm{BM}$ & 2 & 2 \\
\hline CP0835.III.2 & C. aff. jeanesii & BRFT & - & 3 & CM07.II.1.2 & C. trapeziformis & BM & 2 & - \\
\hline CP0835.VIII.2.1 & C. aff. jeanesii & BRFT & 24 & 2 & CM07.II.1.3 & C. trapeziformis & BM & 2 & - \\
\hline CP0835.VIII.2.2 & C. aff. jeanesii & BRFT & 26 & - & SRBG01.I.1 & C. trapeziformis & ANBG & - & 2 \\
\hline CP0835.VIII.2.3 & C. aff. jeanesii & BRFT & 25 & - & SRBG01.II.1 & C. trapeziformis & ANBG & 29 & 2 \\
\hline CP0835.IX.1.3 & C. aff. jeanesii & BRFT & 30 & 3 & SRBG01.II.2 & C. trapeziformis & ANBG & - & 2 \\
\hline CP0835.IX.2.1 & C. aff. jeanesii & BRFT & 31 & 3 & SRBG01.II.3.1 & C. trapeziformis & ANBG & 14 & 2 \\
\hline CP0835.IX.2.2 & C. aff. jeanesii & BRFT & 32 & - & SRBG01.II.3.2 & C. trapeziformis & ANBG & 3 & - \\
\hline CP0835.IX.2.3 & C. aff. jeanesii & BRFT & 28 & - & SRBG01.II.4 & C. trapeziformis & ANBG & - & 2 \\
\hline CP0835.IX.3.2 & C. aff. jeanesii & BRFT & 34 & 3 & SRBM01.I.3.1" & C. trapeziformis & BM & 12 & - \\
\hline CP0835.IX.3.3 & C. aff. jeanesii & BRFT & 35 & - & SRBM01.I.3.2"m & C. trapeziformis & BM & 17 & - \\
\hline CV0836.I.1 & C. valida & BRFT & 20 & 3 & SRBG03.I.3=1" & C. trapeziformis & ANBG & 8 & - \\
\hline CV0836.II.1 & C. valida & BRFT & - & 3 & SRBG03.I.6" & C. trapeziformis & ANBG & 6 & - \\
\hline CV0627.II.1 & C. valida & LR & 23 & 2 & SRBG03.I.7 & C. trapeziformis & ANBG & $16^{\mathrm{a}}$ & - \\
\hline CV0627.II.2 & C. valida & LR & - & 2 & SRBG03.I.8 & C. trapeziformis & ANBG & 16 & - \\
\hline 505.III.1 & C. diphylla & BP1 & - & 2 & SRBG03.II.1 & C. trapeziformis & ANBG & 4 & - \\
\hline 505.III.5 & C. diphylla & BP1 & 11 & 2 & SRBG03.II.2"m & C. trapeziformis & ANBG & $*$ & - \\
\hline 07054.I.1 & C. diphylla & BP1 & - & 2 & SRBG03.II.3" & C. trapeziformis & ANBG & $*$ & - \\
\hline 07054.II.1 & C. diphylla & BP1 & - & 1 & SRBG03.III.1"man & C. trapeziformis & ANBG & 17 & - \\
\hline 07054.VI.1 & C. diphylla & BP1 & - & 2 & SRBG03.III.2 & C. trapeziformis & ANBG & $*$ & - \\
\hline 07050.I.1 & C. diphylla & BP1 & 10 & 1 & SRBG03.III.3 $3^{\text {and }}$ & C. trapeziformis & ANBG & $*$ & - \\
\hline 07048.I.1 & C. diphylla & $\mathrm{KH}$ & - & 2 & SRBG03.III.5 & C. trapeziformis & ANBG & $*$ & - \\
\hline 07053.III.1 & C. diphylla & BP2 & - & 2 & SRBG03.III.6" & C. trapeziformis & ANBG & $*$ & - \\
\hline 07061.I.1 & C. reflexa & WL & 9 & 2 & SRBG03.III.11"m & C. trapeziformis & ANBG & $*$ & - \\
\hline 07061.I.7 & C. reflexa & WL & - & 2 & SRBG03.III.12 & C. trapeziformis & ANBG & 8 & - \\
\hline 07061.III.7 & C. reflexa & WL & - & 2 & SRBG03.III.13 & C. trapeziformis & ANBG & $*$ & - \\
\hline 07071.I.1 & C. reflexa & MI & - & 2 & SRBG03.IV.1"m & C. trapeziformis & ANBG & $*$ & - \\
\hline 07072.II.3 & C. reflexa & MI & - & 2 & SRBG03.IV.2 & C. trapeziformis & ANBG & $*$ & - \\
\hline 07072.II.4 & C. reflexa & MI & - & 2 & SRBG03.IV.3"ח & C. trapeziformis & ANBG & $*$ & - \\
\hline 07033.I.1 & C. seminuda & HR & - & 2 & SRBG03.IV.4 & C. trapeziformis & ANBG & 17 & - \\
\hline 07033.I.2 & C. seminuda & HR & - & 2 & SRBG03.IV.5ㅁㅁ & C. trapeziformis & ANBG & 13 & - \\
\hline 07033.II.1 & C. seminuda & HR & - & 2 & SRBG03.IV.6 & C. trapeziformis & ANBG & 17 & - \\
\hline 07033.II.2.1 & C. seminuda & HR & 5 & 2 & Total & 6 & & 46 & 47 \\
\hline 07033.II.2.2 & C. seminuda & HR & 7 & - & & & & & \\
\hline
\end{tabular}

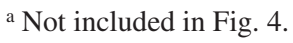

(Everitt, 1977) was applied to test the null hypothesis of no associations among seed germination potential of the three fungal isolates and seed pods of $C$. aff. jeanesii.

\section{RESULTS}

Fungal species associated with Chiloglottis-A total of 47 isolates from 28 plants were obtained from six Chiloglottis species representing 10 sites (Table 1). For the ITS locus, 34 clones were sequenced (GenBank accessions HM196779-HM196813, Appendix 1) from fungal cultures obtained from six Chiloglottis species representing seven sites (Table 2). For the mtLSU locus, 47 symbionts from six Chiloglottis species were sequenced (GenBank accessions HM196772-HM196774,
Appendix 1) representing all 10 sites and 28 plants. The closest BLAST hits on GenBank were Tulasnella tomaculum (KC429) isolated from decaying Pinus sp. wood, T. eichleriana and T. violea, both isolated from P. sylvestris (Table 3). The next closest sequenced relatives isolated from orchids were Epulorhiza albertensis (Epulorhiza $=$ Tulasnella anamorph) ex Platanthera orbiculata.

In the mtLSU phylogenetic analyses, all Chiloglottis fungal sequences formed a monophyletic group of Tulasnella lineages, sister to T. tomaculum with high bootstrap (97\%) and Bayes clade credibility (1.0) values (Fig. 3). For the ITS locus, Chiloglottis fungal sequences formed a highly supported group related to T. tomaculum, T. violae (AY382813), and T. eichleriana (Fig. 4). All the Chiloglottis-derived fungal sequences were 


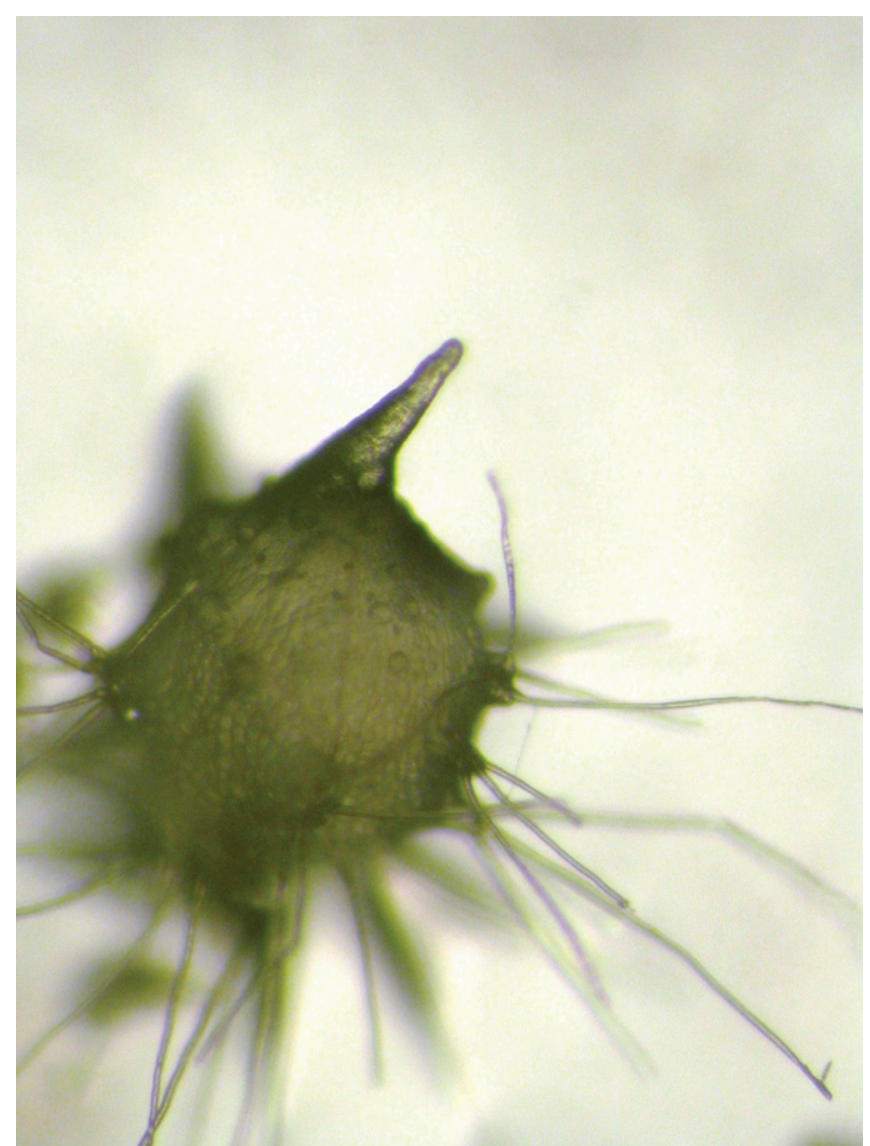

Fig. 2. A late stage 4 protocorm of Chiloglottis aff. jeanesii.

more closely related to each other than to any other Tulasnella species included in the analysis. The Sebacina sp. from GenBank (AD0016351) in the mtLSU tree (Fig. 3) was tentatively identified as a Sebacina sp. (Currah et al., 1990), but most likely it represents a misidentification, as all other sequences belong to Tulasnella or the Tulasnella anamorph genus Epulorhiza, and therefore Tulasnella is monophyletic. Gloeotulasnella is not recognized as different from Tulasnella (Olive, 1957; Roberts, 1994), which is supported by the mtLSU tree placing Gloeotulasnella (syn. Tulasnella) cystidiophora monophyletic within Tulasnella.

Little variation was recorded among mtLSU sequences from the Chiloglottis species, with only three haplotypes recorded among the 47 isolates sequenced (Fig. 3, Table 2). These haplo- types each differed by one polymorphic site only. For the ITS locus, 35 clonal types were identified among 46 ITS clones derived from 21 isolates and direct sequencing of five C. trapeziformis plants (Table 2). Clones derived from the same isolate generally belonged to different ITS haplotypes (e.g., clones of isolates 06082.I.1, CP0835.III.1, CP0835.VIII.2 and SRBG01.II.3). Furthermore, ITS clones derived from isolates associated with the same plant generally also belonged to different haplotypes (e.g., 06082.I.1 and 06082.I.3), although clones derived from isolates obtained from different plants were identical (e.g., haplotype 17 from SRBG03.IV and SRBG03.III from C. trapeziformis at the ANBG site). Haplotype 17 was also found associated with $C$. trapeziformis at the BM site, approximately $2 \mathrm{~km}$ away. In the one other case where the same ITS haplotype was associated with different plants, the individuals belonged to the same species from the same site (haplotype 28 from $C$. aff. jeanesii) (Fig. 4, Table 2).

There was little evidence for patterns of association between haplotypes and particular Chiloglottis species. However, isolates from $C$. aff. jeanesii plants at the BRFT site did form a group that included only one isolate from another Chiloglottis species, C. trapeziformis from site ANBG, SRBG01.II.1 when analyzed with the ITS locus (Fig. 4). This association was confirmed with a contingency $\chi^{2}$ test $\left(\chi^{2}=29.4, \mathrm{df}=1, p=0.001\right)$, rejecting the null hypothesis of no association between haplotypes and the species $C$. trapeziformis and $C$. aff. jeanesii.

Fungal amplification from Chiloglottis trapeziformis tissue - Direct sequencing of the ITS locus with subsequent cloning of fragments (GenBank accessions HM196775-HM196778, Appendix 1) was conducted on five C. trapeziformis plants. Based on BLAST matches on GenBank, 12 of the 23 clones belonged to Tulasnella, with all 12 samples being genetically very similar to the isolates obtained by standard culturing methods (see bold accessions on Fig. 3). Tulasnella sequences were obtained from all five plants. Two plants yielded only Tulasnella sequences. In addition to Tulasnella, three non-Tulasnella or endophytic fungal sequences were found in the tissue of three C. trapeziformis plants, using the ITS1 and ITS4OF primer combination (Table 3). These were classified as uncultured soil fungi with BLAST searches, but when BLAST searches were conducted excluding uncultured samples, BLAST hits were obtained with Trechispora subsphaerospora $(N=6)$, Scleroderma areolatum $(N=3)$, and Mycena hudsoniana $(N=2)$ (Table 3$)$.

Orchid germination trials - The three tested isolates derived from C. valida, C. aff. jeanesii, and C. reflexa were able to induce stage 4 and 5 protocorm development on seed of $C$. aff. jeanesii

TABLE 3. BLAST results showing the top sequence alignment match and corresponding statistics for fungal sequences selectively amplified from tissue segments of Chiloglottis trapeziformis and fungal cultures obtained from Chiloglottis species. ${ }^{*}=$ Representative sequences, $N=$ the number of sequences identical to the representative sequence obtained.

\begin{tabular}{|c|c|c|c|c|c|c|}
\hline ITS clone sequence & Closest BLAST match & Length (bp) & Max score & $\begin{array}{c}\text { Query coverage } \\
(\%)\end{array}$ & E-value & $\begin{array}{c}\text { Max identity } \\
(\%)\end{array}$ \\
\hline *06082.I.1, represents ITS ancestral group & AY373292 Tulasnella eichleriana & 917 & 787 & 83 & 0 & 85 \\
\hline *CP835.III.1.1, represents ITS derived group & AY373292 Tulasnella eichleriana & 918 & 780 & 83 & 0 & 85 \\
\hline$*$ SRBG03.I.7, $N=1$ & AY373296 Tulasnella tomaculum & 559 & 569 & 99 & $4 \mathrm{e}-159$ & 85 \\
\hline$*$ SRBG03.II.1,$N=11$ & AY373292 Tulasnella eichleriana & 862 & 774 & 87 & 0 & 85 \\
\hline$*$ SRBG03.IV. $3, N=6$ & AF347080 Trechispora subsphaerospora & 671 & 355 & 61 & $2 \mathrm{e}-94$ & 83 \\
\hline$*$ SRBG03.III.13, $N=3$ & EU718116 Scleroderma areolatum & 742 & 902 & 88 & 0 & 92 \\
\hline *SRBG03.III.6, $N=2$ & EU846300 Mycena hudsoniana & 457 & 715 & 99 & 0 & 94 \\
\hline
\end{tabular}




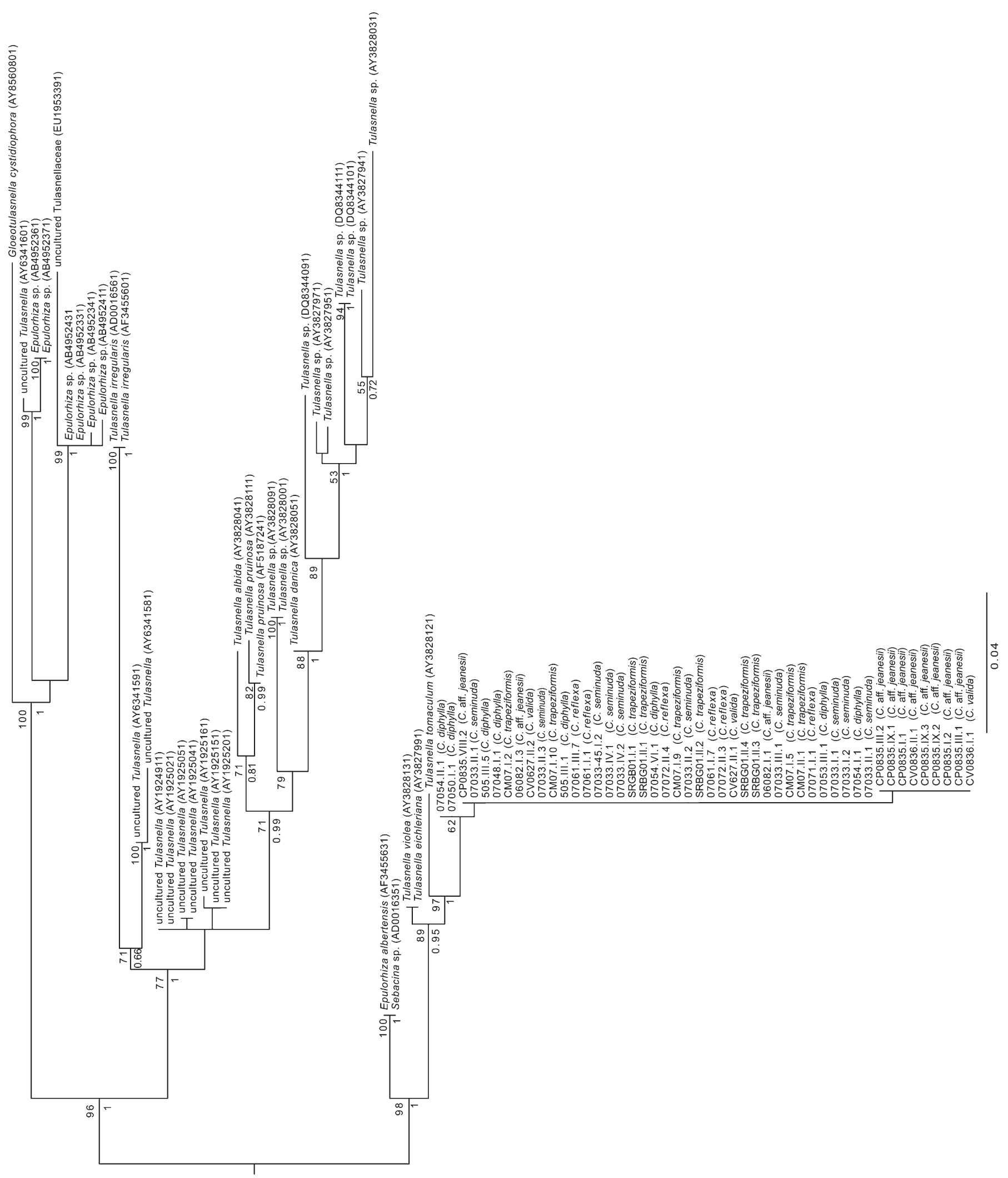

Fig. 3. Maximum likelihood of mtLSU sequences from fungal isolates associated with Chiloglottis species. Bootstrap values are provided above nodes and Bayes clade credibility values below nodes. Only bootstrap values $>50$ and Bayes clade credibility values $>0.7$ are shown. 


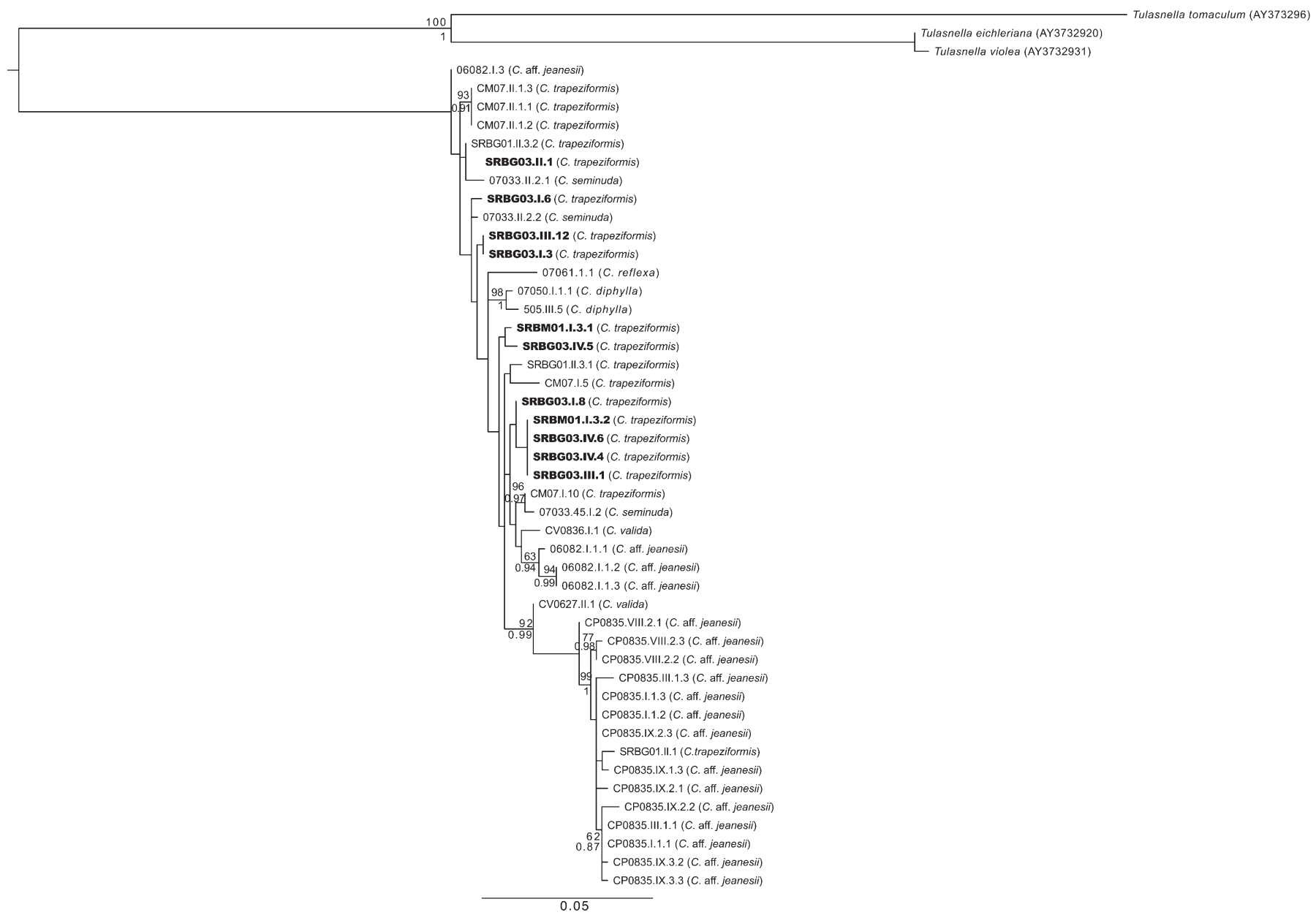

Fig. 4. Maximum likelihood of ITS sequences from fungal isolates associated with Chiloglottis species. Bootstrap values are provided above nodes and Bayes clade credibility values below nodes. Only bootstrap values $>60$ and Bayes clade credibility values $>0.7$ are shown. Fungal sequences obtained with direct sequencing from Chiloglottis trapeziformis are indicated in bold.

(Fig. 5) as well as C. valida (Fig. 6). Both Chiloglottis species varied in the number at stage 4 and 5 protocorm development within and between seed pods (Figs. 5, 6). The highest germination recorded was $23 \%$ on $C$. aff. jeanesii seed pod 7106 with the CV0627.II.2 (ex C. valida, Lowden Rd; derived ITS group—-data not shown) isolate. This isolate also induced the highest recorded percentage germination $(10 \%)$ of seed in $C$. valida, in this case on seed pod 7128 (Fig. 6). However, this same isolate failed to germinate seed of pod 7111 of $C$. aff. jeanesii. Isolate 06082.I.1 (ex $C$. aff. jeanesii: ancestral ITS group) also failed to germinate seed from pods 7118 and 7119 . A contingency $\chi^{2}$ test showed that the null hypothesis of no association in germination potential among the three tested fungal isolates and $C$. aff. jeanesii seed pods 7123 , 7106 , and 7108 was rejected $\left(\chi^{2}=9.2, \mathrm{df}=4, p=0.001\right)$. None of the seed on noncolonized OMA control treatments germinated.

\section{DISCUSSION}

Chiloglottis species have a wide distribution in southeastern Australia ranging from Queensland in the north to Tasmania in the south, and west to South Australia (Jones, 2006). Although we only sampled a subset of the total species from a portion of the genus' range, our sampling included the full breadth of phy- logenetic diversity. We predicted that if fungal mycorrhizal associates have contributed to the diversification of this orchid genus, we would find narrow associations between orchid species and specific fungal species. In the discussion that follows, we evaluate the evidence for this hypothesis. First, we consider the evidence as to whether our sampling methods (via culture) underestimated mycorrhizal diversity in comparison to direct sequencing. Next, we consider the germination potential of the fungal isolates. We then explore the phylogenetic relationships and examine which species and how many are involved in the partnership. Finally, we consider the question of specificity and the evolutionary implications of our findings.

Does direct DNA amplification reveal additional diversity in orchid-fungal associations? - The current mycorrhizal fungal sampling methods employed in this and most other studies are biased toward fast-growing and easily cultured fungi. Consequently, the fungal diversity associated with green orchids may be underestimated (Taylor et al., 2002). Direct amplification of fungi from orchid tissue often reveals a diverse array of fungal species, including various ascomycetes (Otero and Bayman, 2006; Dearnaley, 2007). Therefore, direct sequencing from $C$. trapeziformis tissue was expected to reveal a wider diversity of associated fungal species than those found using our standard 


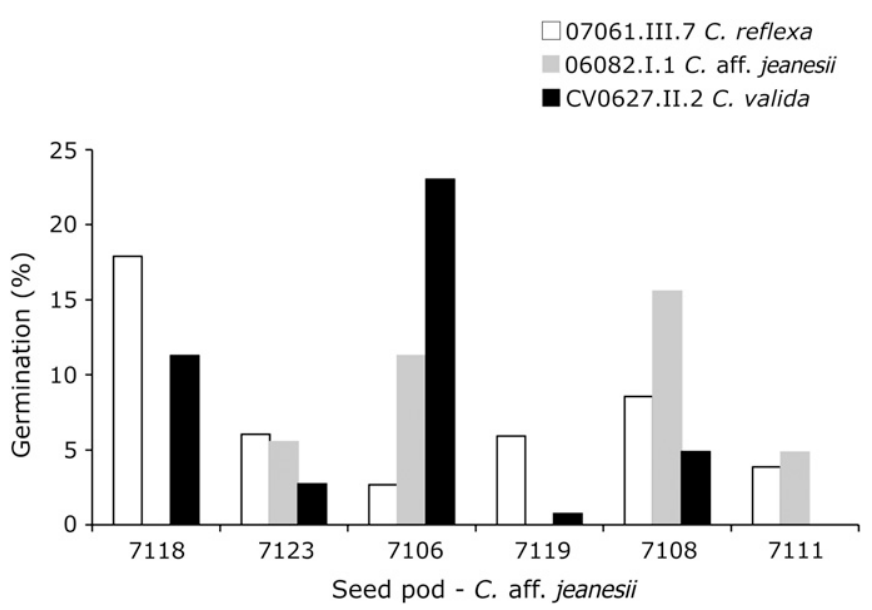

Fig. 5. Percentage germination of seed of Chiloglottis aff. jeanesii in association with three Tulasnella sp. isolates 07061.III.7 (ex Chiloglottis reflexa), 06082.I.1 (ex C. aff. jeanesii and CV0627.II.2 (ex Chiloglottis valida).

culture method. The majority of ITS clones obtained by direct sequencing in this study were very closely related to the Tulasnella lineage extracted via standard culture methods. BLAST searches did, however, indicate the presence of several other fungal symbionts as unidentified, uncultured species. Excluding uncultured samples from the BLAST searches resulted in hits with Threchispora, which is not considered mycorrhizal (Allen et al., 2003), Scleroderma, which is a common tree mycorrhizal symbiont (Dell et al., 1990), and Mycena, which is normally a free-living saprophyte exploited by Gastrodia orchids as a mycorrhizal symbiont (Ogura-Tsujita et al., 2009). Whether the uncultured fungal species from this study can indeed act as mycorrhizal symbionts in Chiloglottis is unknown and requires further investigation using techniques such as seed baiting (Batty et al., 2006) and reisolation, or direct amplification of protocormic fungi. The evidence here does not indicate a substantial underestimate of fungal diversity by our culture methods.

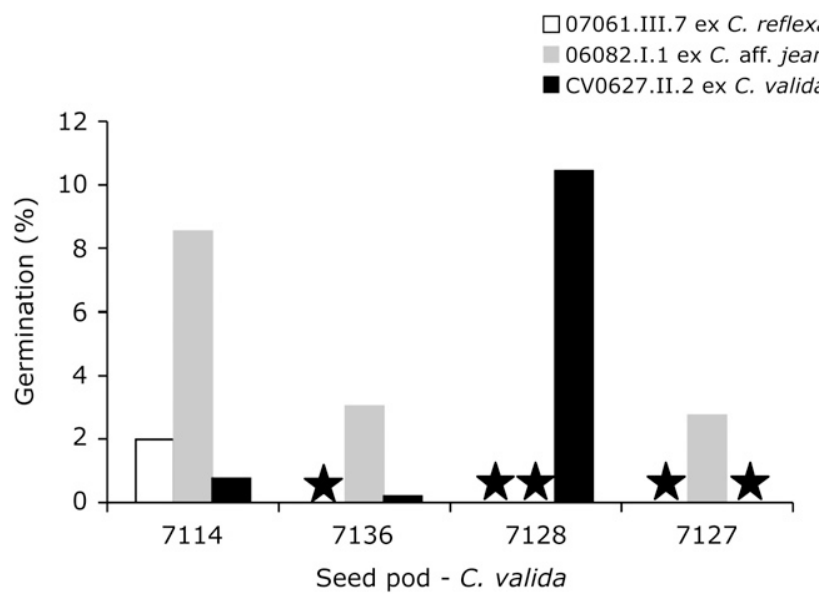

Fig. 6. Percentage germination of seed of Chiloglottis valida in association with three Tulasnella isolates 07061.III.7 (ex Chiloglottis reflexa), 06082.I.1 (ex Chiloglottis aff. jeanesii), CV627.II.2 (ex C. valida). Star = isolate treatments lost to contamination.
Direct sequencing is also useful to determine whether protocorm fungal composition is different for fungal symbionts established in adult plants (Batty et al., 2006). Mycorrhizal associations of Cephalanthera damasonium, C. longifolia (Bidartondo and Read, 2008), and Caladenia formosa (Huynh et al., 2009) have been shown to differ between adult and protocormic stages. Furthermore, in Caladenia formosa, fungi with the highest germination rates did not necessarily result in the greatest survival and growth 1 year after germination (Huynh et al., 2009). Because direct sequencing was only carried out on material collected from established adult plants, our study could have missed a portion of fungal diversity interacting at earlier orchid growth stages despite our cultured isolates nevertheless initiating germination of orchid seed.

What is the germination potential of the fungal isolates?-Seed germination trials confirmed the capability of the Tulasnella isolates to enable seed germination of two orchid species tested: $C$. valida and $C$. aff. jeanesii. Our experiments confirmed that all the tested Tulasnella fungi isolated from different plants at different sites could initiate germination, although possible isolate by Chiloglottis species or seed pod interaction was observed. Very few seeds reached advanced germination stages under the experimental conditions used in this study, with highest germination of seeds in $C$. aff. jeanesii being $23 \%$ and $C$. valida just $10 \%$. These low seed germination rates are not unusual; low rates were also observed for Caladenia (4-21\%) (Huynh et al., 2009) and for Vanilla and Ionopsis (2-7\%) (Porras-Alfaro and Bayman, 2007), whereas germination rates ranged between approximately $37-90 \%$ for tropical epiphytes (Otero et al., 2004). Factors responsible for low seed germination rates are unknown and need further investigation.

The variation in germination among orchid seed pods and fungal isolates may simply be due to random error, or it may indicate that the Tulasnella isolates in this study represent genetically different strains that confer differences in mycorrhizal compatibility or fitness. Similar variation in germination ability of different Ceratobasidium isolates has been reported in the epiphytic orchid Tolumnia variegata, with only 5 of 10 seed pods germinating (Otero et al., 2005). Significant variation in germination effectiveness among fungal isolates of the same species on Caladenia formosa was also observed (Huynh et al., 2009). An expansion of the current study to investigate potential interactions among fungal isolates and Chiloglottis species and genotypes is required.

Which fungi and how many fungal taxa are involved in the partnership? - In our phylogenetic analysis of the mitochondrial (mtLSU) DNA locus, all Chiloglottis-derived fungal sequences formed a single clade sister to other Tulasnella species, with only three haplotypes represented among the 47 isolates. Compared with mtLSU, more sequence variation was encountered at the ITS locus with a total of 35 haplotypes detected among the 46 ITS clones. Some phylogeographic structure was evident, with the ITS haplotypes falling into two main groups. The first group representing the ancestral lineages in the tree included isolates from all six Chiloglottis species sampled, while the derived lineages, supported by 0.99 Bayes clade credibility values, represented a narrower range of species including isolates from $C$. aff. jeanesii (CP0835 from site BRFT) and a clone each from $C$. valida (CV0627.II.1) and C. trapeziformis (SRBG01.II.1). The grouping of $C$. aff. jeanesii in the derived lineages on the tree is of interest since some of the same isolates 
also clustered together in the mtLSU analysis. Despite some genetic structure, the six Chiloglottis species are associated with a narrow monophyletic group of Tulasnella lineages.

While all six Chiloglottis species hosted a narrow monophyletic group of Tulasnella lineages, we did detect some genetic differences among fungal isolates, particularly in the ITS for which we identified 35 haplotypes from 46 clones representing 21 isolates. None of the haplotypes were shared among Chiloglottis species or sites, except for ITS haplotype 17, which was shared between the Black Mountain (BM) and Botanical Garden (ANBG) locations of $C$. trapeziformis. These sites are separated by approximately $2 \mathrm{~km}$, and haplotype sharing may be explained by the possibility of plants at the BG site being artificially sourced from a colony on Black Mountain. Chiloglottis individuals were also often associated with more than one ITS clonal type, reflecting the diversity within the ITS locus. Sharing of haplotypes was rare even between plants of the same species at the same site with the only two examples being haplotype 17 on $C$. trapeziformis and haplotype 28 on $C$. aff. jeanesii.

Warcup suggested that Chiloglottis is associated with T. cruciata and T. allantospora as well as unidentified Tulasnella species (Warcup, 1981); however, in a later review, Warcup (1990) claimed the mycorrhizal symbiont of Chiloglottis as unknown. The present study confirms the preliminary results of Warcup (1981) that the mycorrhizal symbiont of Chiloglottis is a Tulasnella species. While all of our isolates formed a single ITS clade well separated from Tulasnella tomaculum, the identity of this taxon remains unknown because we are dependent on reference sequences in GenBank for sequence identification. This dependence on reference sequences to identify fungal species, highlights the need for a larger sampling to improve the phylogeny of Tulasnella to aid better identification of orchid mycorrhizal symbionts.

The question of species delineation, especially in the case of cryptic species that by definition lack obvious morphological differences, is a challenging one. Despite the promise of DNAbased taxonomy, the use of DNA evidence on its own to identify and discover plant and animal species remains highly controversial (Wheeler, 2005; Will et al., 2005). The problem of species delineation in fungi is even more problematic than for many plants and animals (Suarez et al., 2008) because some fungi may simply be unculturable and therefore can only be found by direct DNA sequencing. The problem is further compounded by a general lack of informative "species-level" genetic markers in fungi. One rule of thumb that has been applied to ITS fungal sequences is to apply a threshold of $3 \%$ sequence divergence to species boundaries (Nilsson et al., 2008; Peay et al., 2008). Indeed, Tulasnella clades claimed to be specific to their associated orchids Goodyera and Liparis in North America, were separated by ITS differences of approximately 8-10\% (McCormick et al., 2004). By contrast, all of the Tulasnella isolates from Chiloglottis in this study differed at most by $1.6 \%$ sequence divergence. Therefore, by the $3 \%$ criterion (Nilsson et al., 2008; Peay et al., 2008), all of the Tulasnella isolates from Chiloglottis would be considered to belong to a single ITS-defined species if we were to strictly follow this rule.

An interesting anomaly noted in this study is that the GenBank ITS sequences attributed to $T$. eichleriana and $T$. violea are extremely similar and well below the $3 \%$ threshold to characterize different species (see Fig. 3). Two other studies (McCormick et al., 2004; Porras-Alfaro and Bayman, 2007) also found this pattern using GenBank sequences. In McCormick et al., (2004), it is evident that three putative $T$. violea sequences differed markedly from each other, with one sequence identical to T. eichleriana, as found in this study. We suggest three possible explanations for this anomaly: (1) T. violea as defined morphologically is polyphyletic; (2) ITS markers cannot distinguish between some species; or (3) the accessions were misidentified. It is beyond the scope of the current study to resolve this issue; nonetheless, it is evident that it will be helpful to develop additional informative genetic markers that provide resolution below the species level in Tulasnella and other fungi. While the taxonomic status of the Chiloglottis isolates cannot be fully resolved in this present study, there is no doubt that Chiloglottis species are associated with a narrow monophyletic group of Tulasnella lineages.

Patterns of orchid-fungal specificity: Ecological and evolutionary implications? - Many studies of orchid mycorrhizal associations suggest a specific association between orchid and symbiont and draw conclusions about specialization (Selosse et al., 2002; Girlanda et al., 2006; Suarez et al., 2006; Bonnardeaux et al., 2007; Shefferson et al., 2007). However, one problem in comparing among studies is that the terms specificity and specialization are often used differently. For example, specialization is sometimes taken to mean an association of phylogenetically closely related fungal species among different orchid species in the same genus. Specificity is also characterized as an association of a related group of fungi with one orchid species, e.g., 20 Russula spp. on Corallorhiza maculata (Taylor and Bruns, 1999). In other cases, it is concluded that a specific mycorrhizal association exists when the same phylogenetic group of fungi are recovered from repeated sampling of the orchid species over a geographic range (e.g., Rasmussen, 2002).

This Tulasnella-Chiloglottis association appears to be one of the first known cases in which such a narrow monophyletic group of fungal lineages is associated with multiple orchid species spanning a broad survey of the genus. In a recent study, Barrett and coworkers (Barrett et al., 2010) also found that a single fungal species, Tomentella fuscocinerea, associates with a species complex of the mycoheterotrophic orchid Corallorhiza striata (likely representing three orchid species and further varieties). Although not as many species of Corallorhiza were sampled as for our Chiloglottis study, it may suggest that future studies will find a similar trend of narrow fungal associations across a wide array of species. On the other hand, if the $3 \%$ (Nilsson et al., 2008; Peay et al., 2008) or 2.5\% (Barrett et al., 2010) ITS divergence criterion is applied to this case of Tomentella fuscocinerea, up to 12 cryptic symbiont fungal species of Corallorhiza may be circumscribed within T. fuscocinerea (Barrett et al., 2010).

Mycorrhizal associations in the photosynthetic orchid genus Cypripedium have been investigated across the phylogenetic breadth of the genus with sampling spanning from North America to Europe (Shefferson et al., 2005, 2007). This research revealed narrow associations with mycorrhizal partners for some members such as C. calceolus; however, other orchid species associated with multiple clades within a fungal genus or even across several genera in the case of $C$. californicum (Shefferson et al., 2005, 2007). These studies used more slowly evolving markers compared to the current study: 5.8S, mtLSU (Shefferson et al., 2007) and nucLSU (Shefferson et al., 2005), and as a consequence, the extent of fungal diversity may have been underestimated.

A narrow phylogenetic breadth of orchid mycorrhizae has also been reported in several cases involving studies of a single 
species of orchids, including Eulophia zollingeri, which associates with a fungal species complex across Japan, Myanmar, and Tawain (Ogura-Tsujita and Yukawa, 2008). A similar pattern in fungal diversity was found in epiphytic orchid species Ionopsis utricularioides that associate with very narrow clades within Ceratobasidium (Otero et al., 2007).

These examples demonstrate variation in the degree of specificity between orchid and fungal symbionts, ranging from apparent one to one relationships between orchid and a specific fungus, through cases such as Chiloglottis that has multiple orchid species associated with a narrow group of lineages, to cases of an orchid species associated with a diverse array of fungal species. It is clear that the Chiloglottis-Tulasnella example represents the most extreme case of specificity found so far, with a monophyletic group of lineages, possibly representing one species only, associated with a broad survey of Chiloglottis species.

It is unclear why specific mycorrhizal relationships exist and what the advantage of such a specific association would be. The advantages of specific mycocrrhizal relationships are elegantly discussed in Barrett et al. (2010) for the symbionts of Corallorhiza striata, proposing two hypotheses for this phenomenon. The first is that high specificity is selected for because it simplifies the interaction (e.g., orchids do not have to deal with different defense systems of symbionts) (Thompson, 1994) and provides an optimum food source (e.g., the chosen symbiont provides superior nutritional quality) (Rasmussen and Rasmussen, 2009). The second hypothesis posed by Barrett et al. (2010) is that the symbionts might have narrow geographic distributions, preventing association with the orchids, thereby forcing specificity by the orchid due to the absence of putative symbionts. However, if geographic ranges for orchids and fungi are patchy, then opportunities for symbiosis in areas of overlap will be few and might actually favor generalization, not specialization as suggested. In the absence of data concerning, for example, mycorrhizal fitness, differences in nutrient uptake ability of mycorrhizal strains and species and the distribution/availability of symbionts, it is impossible to discern between these two hypotheses. Indeed, very specific relationships with mycorrhizae may be dependent on the saprophytic fungal life cycle of some fungi, which could provide suitable habitat for terrestrial orchids by decomposing fallen debris from forest trees (OguraTsujita and Yukawa, 2008).

Patterns of fungal specificity and sexual deception in Australian orchids? - It is of interest to ask whether an association of multiple sexually deceptive orchid species with a narrow group of fungal lineages, as discovered in Chiloglottis, might be a general pattern among Australian, sexually deceptive orchids. Chiloglottis belongs to the tribe Drakaeinae, which is a monophyletic clade of exclusively sexually deceptive genera including Arthrochilus, Chiloglottis, Drakaea, Paracaleana, Caleana, and Spiculaea. Isolate studies by Warcup (1981) indicated that Arthrochilus, Drakaea, and Chiloglottis (species were not listed) each associated with several species of Tulasnella, and Caleana with one Tulasnella species. However, the identity of these mycorrhizal symbionts and the pattern and degree of specificity have not yet been confirmed by molecular phylogenetic analysis. A pilot molecular study has indicated that multiple Drakaea species may also be associated with a narrow group of Tulasnella lineages (C. C. Linde, R. D. Phillips, and R. Peakall, unpublished data). Thus, mycorrhizal specificity in sexually deceptive orchids may be a more general pattern, at least in the tribe Drakaeinae.
The next closest related orchid tribes to the Drakaeinae are Thelymitrinae and Cryptostylidinae (Kores et al., 2001), although only Cryptostylis species are sexually deceptive. Thelymitra species are known to associate with a number of Tulasnella species. Beyond them, the next closest is Caladenia and Diuris in the Diuridinae-Caladeninae. Caladenia associates with a broad species complex within the Sebacinaceae (e.g., Bougoure et al., 2005; Bonnardeaux et al., 2007), while Diuris species associate with a narrow group of Tulasnella lineages (Smith et al., 2010). Pyrorchis nigricans, which belongs to a clade sister to Drakaeinae (Kores et al., 2001), was found to have some of the most diverse associations with multiple mycorrhizal genera including a relative of Tulasnella danica (Bonnardeaux et al., 2007).

The diverse Australian terrestrial orchid genus Caladenia with some 300 species is unique among orchid genera worldwide in that it contains species that employ pollination by food reward, food deception, and sexual deception (Phillips et al., 2009). As such, this genus may provide a unique model system to assess whether there is any relationship between patterns of fungal specificity and an orchid's pollination mechanism.

Implications of our findings for orchid diversification-In this study, we made the unexpected discovery that six species of Chiloglottis, representing a broad survey across the genus, were associated with a narrow monophyletic group of Tulasnella mycorrhizal symbiont lineages. This finding may explain the frequent observation that two or more Chiloglottis species can co-occur, in some cases even growing and coflowering in mixed colonies. It is further likely that the Chiloglottis-Tulasnella mycorrhizae are common and widespread in Australia, because Tulasnella spp. are known to survive saprophytically and are therefore not dependent on the orchid for survival. If true, this might contribute to Chiloglottis having such a wide distribution across southeastern Australia. There is evidence from other orchid-fungal studies that a widespread distribution of the fungal associations is correlated with orchid distribution and abundance (Ogura-Tsujita and Yukawa, 2008; Barrett et al., 2010). Furthermore, this study may have restoration implications for propagation of rare or threatened Chiloglottis species such as $C$. platyptera and $C$. anaticeps listed as vulnerable and endangered. Future research is needed to clarify the nature of mycorrhizal specificity with these species and whether the presence of compatible fungi is a significant limiting factor in contributing to their rarity.

Our finding that multiple species of sexually deceptive Chiloglottis are associated with a narrow group of fungi may be explained by the process of speciation in the genus. Peakall et al. (2010) have shown that pollinator specificity and, consequently, reproductive isolation, has a strong chemical basis, especially among sympatric Chiloglottis species that use different semiochemicals to attract their specific pollinators. Mapping of chemistry onto the phylogeny has further revealed that chemical change is frequently associated with speciation. However, the structural relatedness of the compounds involved suggests only minor modifications of a common biochemical pathway. Therefore, rapid pollinator-driven speciation appears plausible in this system (Peakall et al., 2010).

Thus, the specific pollination system of Chiloglottis, rather than specific orchid-fungal interactions, appears to have been the key driving force in the diversification of the genus. Nonetheless, the ability of multiple Chiloglottis species to associate with a narrow group of fungal lineages enables the sympatric distribution of multiple orchid species. Rapid pollinator-mediated 
speciation might act in such a way as to quickly result in prezygotic reproductive barriers between incipient species without interrupting the existing associations between orchid and fungus lineages. Indeed, the maintained specialization of Chiloglottis on a narrow phylogenetic range of symbionts could be considered evidence that speciation has occurred rapidly.

The maintenance of orchid association with a specific and narrow lineage of fungi through speciation processes may therefore be contingent on the form of speciation involved and the rate of divergence. Rapid pollinator-mediated selection will be more likely to conserve orchid-fungus associations than more long-term processes such as ecological speciation or vicariance by which lineages might divide over a longer period of time so that both orchid and fungus species observed today have had more opportunity for drift, phyletic change, and adaptation to contribute to divergent mychorrizhal associations.

\section{LITERATURE CITED}

Allen, T. R., T. Millar, S. M. Berch, and M. L. Berbee. 2003. Culturing and direct DNA extraction find different fungi from the same ericoid mycorrhizal roots. New Phytologist 160: 255-272.

ARditTI, J. 1992. Fundamentals of orchid biology. Wiley, New York, New York, USA.

Barrett, C. F., J. V. Freudenstein, D. L. Taylor, and U. Kõlualg. 2010. Rangewide analysis of fungal associations in the fully mycoheterotrophic Corallorhiza striata complex (Orchidaceae) reveals extreme specificity on ectomycorrhizalTomentella (Thelephoraceae) across North America. American Journal of Botany 97: 628-643.

Barrett, J. A. 1986. Host-parasite interactions and systematics. In A. R. Stone and D. L. Hawksworth [eds.], Coevolution and systematics, 1-17. Clarendon Press, Oxford, UK.

Batty, A. L., M. C. Brundrett, K. W. Dixon, and K. Sivasithamparam. 2006. New methods to improve symbiotic propagation of temperate terrestrial orchid seedlings from axenic culture to soil. Australian Journal of Botany 54: 367-374.

Bidartondo, M. I. 2005. The evolutionary ecology of mycoheterotrophy. New Phytologist 167: 335-352.

Bidartondo, M. I., AND T. D. BRUns. 2001. Extreme specificity in epiparasitic Monotropoideae (Ericaceae): Widespread phylogenetic and geographical structure. Molecular Ecology 10: 2285-2295.

Bidartondo, M. I., AND D. J. READ. 2008. Fungal specificity bottlenecks during orchid germination and development. Molecular Ecology 17: 3707-3716.

Bonnardeaux, Y., M. Brundrett, A. Batty, K. Dixon, J. Koch, And K. Sivasithamparam. 2007. Diversity of mycorrhizal fungi of terrestrial orchids: Compatibility webs, brief encounters, lasting relationships and alien invasions. Mycological Research 111: 51-61.

Bougoure, J. J., D. S. Bougoure, J. W. G. Cairney, and J. D. W. DEARNALEY. 2005. ITS-RFLP and sequence analysis of endophytes from Acianthus, Caladenia and Pterostylis (Orchidaceae) in southeastern Queensland. Mycological Research 109: 452-460.

Bower, C. C. 1996. Demonstration of pollinator-mediated reproductive isolation in sexually deceptive species of Chiloglottis (Orchidaceae: Caladeniinae). Australian Journal of Botany 44: 15-33.

Bower, C. C. 2006. Specific pollinators reveal a cryptic taxon in the bird orchid, Chiloglottis valida sensu lato (Orchidaceae) in south-eastern Australia. Australian Journal of Botany 54: 53-64.

Bower, C. C., AND G. R. Brown. 2009. Pollinator specificity, cryptic species and geographical patterns in pollinator responses to sexually deceptive orchids in the genus Chiloglottis: The Chiloglottis gunnii complex. Australian Journal of Botany 57: 37-55.

Bruns, T. D., T. M. Szaro, M. Gardes, K. W. Cullings, J. J. Pan, D. L. TAYLOR, T. R. HORTON, ET AL. 1998. A sequence database for the identification of ectomycorrhizal basidiomycetes by phylogenetic analysis. Molecular Ecology 7: 257-272.
Cameron, D. D., I. Johnson, J. R. Leake, and D. J. Read. 2007. Mycorrhizal acquisition of inorganic phosphorus by the green-leaved terrestrial orchid Goodyera repens. Annals of Botany 99: 831-834.

Cameron, D. D., J. R. Leake, And D. J. Read. 2006. Mutualistic mycorrhiza in orchids: Evidence from plant-fungus carbon and nitrogen transfers in the green-leaved terrestrial orchid Goodyera repens. New Phytologist 171: 405-416.

Cameron, D. D., K. Preiss, G. Gebauer, and D. J. Read. 2009. The chlorophyl-containing orchid Corallorhiza trifida derives little carbon through photosynthesis. New Phytologist 183: 358-364.

Clements, M. A., And R. K. Ellyard. 1979. The symbiotic germination of Australian terrestrial orchids. American Orchid Society Bulletin 48: 810-816.

Cozzolino, S., AND A. Widmer. 2005. Orchid diversity: An evolutionary consequence of deception? Trends in Ecology \& Evolution 20: 487-494.

Currah, R. S., E. A. Smreciu, and S. Hambleton. 1990. Mycorrhizae and mycorrhal fungi of boreal species of Platanthera and Coeloglossum (Orchidaceae). Canadian Journal of Botany 68: 1171-1181.

Dearnaley, J. D. W. 2007. Further advances in orchid mychorrhizal research. Mycorrhiza 17: 475-486.

Dell, B., N. Malajcuk, T. S. Grove, and G. T. Thompson. 1990. Development and function of Pisolithus and Scleroderma ectomycorrhizas formed in vivo with Allocasuarina, Casuarina and Eucalyptus. Mycorrhiza 5: 129-138.

EveritT, B. S. 1977. The analysis of contingency tables. Chapman and Hall, London, UK.

Franke, S., F. Ibarra, C. M. Schulz, R. Twelle, J. Poldy, R. Barrow, R. Peakall, and F. P. Schiestl. 2009. The discovery of 2,5-dialkylcyclohexan-1,3-diones as a new class of natural products. Proceedings of the National Academy of Sciences, USA 106: 8877-8882.

Girlanda, M., M. A. Selosse, D. Cafasso, F. Brilli, S. Delfine, R. FABbian, S. Ghignone, ET AL. 2006. Inefficient photosynthesis in the Mediterranean orchid Limodorum abortivum is mirrored by specific association to ectomycorrhizal Russulaceae. Molecular Ecology 15: 491-504.

HadLey, G. 1970. Non-specificity of symbiotic infection in orchid mycorrhiza. New Phytologist 69: 1015-1023.

Harley, J. L., AND S. E. Smith. 1983. Mycorrhizal symbiosis. Academic Press, London, UK.

Huynh, T. T., R. Thomson, C. B. McLean, and A. C. Lawrie. 2009. Functional and genetic diversity of mycorrhizal fungi from single plants of Caladenia formosa (Orchidaceae). Annals of Botany 104: $757-765$.

Hynson, N. A., K. Preiss, and G. Gebauer. 2009. Is it better to give than to receive? A stable isotope perspective on orchid-fungal carbon transport in the green orchid species Goodyera repens and Goodyera oblongifolia. New Phytologist 182: 8-11.

JONES, D. L. 2006. A complete guide to the native orchids of Australia, including the island territories. Reed New Holland, Sydney, Australia.

Kores, P. J., M. Molvray, P. H. Weston, S. D. Hopper, A. P. Brown, K. M. Cameron, AND M. W. Chase. 2001. A phylogenetic analysis of Diurideae (Orchidaceae) based on plastid DNA sequence data. American Journal of Botany 88: 1903-1914.

LEE, S. B., AND J. W. TAYLOR. 1990. Isolation of DNA from fungal mycelia and single spores. In M. A. Innis, D. H. Gelfand, J. J. Sninsky, and T. J. White [eds.], PCR protocols: A guide to methods and applications, 282-287. Academic Press, San Diego, California, USA.

Mant, J., R. Peakall, and P. H. Weston. 2005. Specific pollinator attraction and the diversification of sexually deceptive Chiloglottis (Orchidaceae). Plant Systematics and Evolution 253: 185-200.

Mant, J. G., F. P. Schiestl, R. Peakall, and P. H. Weston. 2002. A phylogenetic study of pollinator conservatism among sexually deceptive orchids. Evolution 56: 888-898.

McCormick, M. K., D. F. Whigham, and J. O’Neil. 2004. Mycorrhizal diversity in Photosynthetic terrestrial orchids. New Phytologist 163: 425-438.

Morgenstern, B., S. J. Prohaska, D. Pohler, and P. F. Stadler. 2006. Multiple sequence alignment with user-defined anchor points. Algorithms for Molecular Biology; AMB 1: 6 
Nilsson, R. H., E. Kristiansson, M. Ryberg, N. Hallenberg, and K.-H. LARSSON. 2008. Intraspecific ITS variability in the kingdom Fungi as expressed in the international sequence databases and its implications for molecular species identification. Evolutionary Bioinformatics 4: 193-201.

Ogura-Tsujita, Y., G. Gebauer, T. Hashimoto, H. Umata, and T. YUKAWA. 2009. Evidence for novel and specialized mycorrhizal parasitism: The orchid Gastrodia confusa gains carbon from saprotrophic Mycena. Proceedings of the Royal Society of London, B, Biological Sciences 22: 761-767.

Ogura-Tsujita, Y., and T. Yukawa. 2008. High mycorrhizal specificity in a widespread mycoheterotrophic plant, Eulophia zollingeri (Orchidaceae). American Journal of Botany 95: 93-97.

Olive, L. S. 1957. Tulasnellaceae of Tahiti. A revision of the family. Mycologia 49: 663-679.

Otero, J. T., J. D. Ackerman, and P. Bayman. 2004. Differences in mycorrhizal preferences between tropical orchids. Molecular Ecology 13: 2393-2404.

Otero, J. T., ANd P. BAyman. 2006. Microbial endophytes of orchid roots. In B. J. E. Schulz, C. J. C. Boyle, and T. N. Sieber [eds.], Mycorrhizal root endophytes, 153-177. Springer-Verlag, Berlin, Germany.

Otero, J. T., P. Bayman, and J. D. Ackerman. 2005. Variation in mycorrhizal performance in the epiphytic orchid Tolumnia variegata in vitro: The potential for natural selection. Molecular Ecology 19: 29-43.

Otero, J. T., and N. S. Flanagan. 2006. Orchid diversity-Beyond deception. Trends in Ecology \& Evolution 21: 64-65.

Otero, J. T., N. S. Flanagan, E. A. Herre, J. D. Ackerman, and P. BAYMAN. 2007. Widespread mycorrhizal specificity correlates to mycorrhizal function in the neotropical, epiphytic orchid Ionopsis utricularioides (Orchidaceae). American Journal of Botany 94: 1944-1950.

Peakall, R. 1990. Responses of male Zaspilothynnus trilobatus Turner wasps to females and the sexually deceptive orchid it pollinates. Functional Ecology 4: 159-167.

Peakall, R. 2007. Speciation in the Orchidaceae: Confronting the challenges. Molecular Ecology 16: 2834-2837.

Peakall, R., AND A. J. Beattie. 1996. Ecological and genetic consequences of pollination by sexual deception in the orchid Caladenia tentactulata. Evolution 50: 2207-2220.

Peakall, R., C. C. Bower, A. E. Logan, and H. I. Nicol. 1997. Confirmation of the hybrid origin of Chiloglottis $\times$ pescottiana (Orchidaceae: Diuridae). 1. Genetic and morphometric evidence. Australian Journal of Botany 45: 839-855.

Peakall, R., D. Ebert, J. Poldy, R. A. Barrow, W. Francke, C. C. Bower, AND F. P. Schiestl. 2010. Pollinator specificity, floral odour chemistry and the phylogeny of Australian sexually deceptive Chiloglottis orchids: Implications for pollinator-driven speciation. New Phytologist. Online ahead of print.

Peakall, R., L. Jones, C. C. Bower, And B. G. Mackey. 2002. Bioclimatic assessment of the geographic and climatic limits to hybridisation in a sexually deceptive orchid system. Australian Journal of Botany 50: 21-30.

Peay, K. G., P. G. Kennedy, and T. D. Bruns. 2008. Fungal community ecology: A hybrid beast with a molecular master. BioScience 58: 799-810.

Phillips, R. D., R. Faast, C. C. Bower, G. R. Brown, and R. Peakall. 2009. Implications of pollination by food advertisement and sexual deception for pollinator specificity, fruit set, population genetics and conservation of Caladenia (Orchidaceae). Australian Journal of Botany 57: 287-306.

Porras-Alfaro, A., ANd P. Bayman. 2007. Mycorrhizal fungi of Vanilla: Diversity, specificity and effects on seed germination and plant growth. Mycologia 99: 510-525.

Rambaut, A. 1996. Se-Al. Sequence alignment editor v2.0 [computer program]. Website http://tree.bio.ed.ac.uk/software/seal.

Ramsay, R. R., K. Sivasithamparam, and K. W. Dixon. 1986. Patterns of infection and endophytes associated with Western Australian orchids. Lindleyana 1: 203-214.
RASMussen, H. N. 2002. Recent developments in the study of orchid mycorrhiza. Plant and Soil 244: 149-163.

Rasmussen, H. N., AND F. N. RASmussen. 2009. Orchid mycorrhiza: Implications of a mycophagous life style. Oikos 118: 334-345.

RoberTs, P. 1994. Globose and ellipsoid-spored Tulasnella species from Devon and Surrey, with a key to the genus in Europe. Mycological Research 98: 1431-1452.

RoberTs, P. 1999. Rhizoctonia-forming fungi: A taxonomic guide. Royal Botanic Gardens, Kew, UK.

Ronquist, F., AND J. P. Huelsenbeck. 2003. MrBayes 3: Bayesian phylogenetic inference under mixed models. Bioinformatics 19: 1572-1574.

Schiestl, F. P., R. Peakall, J. G. Mant, F. Ibarra, C. Schulz, S. Franke, AND W. Francke. 2003. The chemistry of sexual deception in an orchid-wasp pollination system. Science 302: 437-438.

Scopece, G., G. Musaccioo, A. Widmer, and S. Cozzolino. 2007. Patterns of reproductive isolation in Mediterranean deceptive orchids. Evolution 61: 2623-2642.

Selosse, M.-A., M. Weiss, J.-L. Jany, And A. Tillier. 2002. Communities and populations of sebacinoid basidiomycetes associated with the achlorophyllous orchid Neottia nidus-avis (L.) L.C.M Rich. and neighbouring tree ectomycorrhizae. Molecular Ecology 11: 1831-1844.

Shefferson, R. P., D. L. Taylor, M. Weiss, S. Garnica, M. K. McCormick, S. Adams, H. M. Gray, et al. 2007. The evolutionary history of mycorrhizal specificity among lady's slipper orchids. Evolution 61: 1380-1390.

Shefferson, R., P., M. Weiss, T. Kull, and D. L. Taylor. 2005. High specificity generally characterizes mycorrhizal association in rare lady's slipper orchids, genus Cypripedium. Molecular Ecology 14: 613-626.

Smith, Z. F., E. A. James, and C. B. McLean. 2010. Mycorrhizal specificity of Diuris fragrantissima (Orchidaceae) and persistence in a reintroduced population. Australian Journal of Botany 58: 97-106.

Stamatakis, A., P. Hoover, and J. Rougemont. 2008. A rapid bootstrap algorithm for the RAxML web servers. Systematic Biology 57: $758-771$.

Suarez, J. P., M. Weiss, A. Abele, S. Garnica, F. Oberwinkler, And I. KоттKE. 2006. Diverse tulasnelloid fungi from mycorrhizas wite epiphytic orchids in an Andean cloud forest. Mycological Research 110: 1257-1270.

Suarez, J. P., M. Weiss, M. Abele, S. Garnica, F. Oberwinkler, and I. KotTKe. 2008. Members of Sebacinales subgroup B form mycorrhizae with epiphytic orchids in a neotropical mountain rain forest. Mycological Progress 7: 75-85.

TAYLOR, D. L. 1997. The evolution of myco-heterotrophy and specificity in some North Amercian orchids. University of California at Berkeley, Berkeley, California, USA.

TAYLOR, D. L. 2004. Myco-heterotroph-fungus marriages-Is fidelity over-rated? New Phytologist 163: 217-221.

TAYlor, D. L., AND T. D. BRUns. 1999. Population, habitat and genetic correlates of mycorrhizal specialization in the 'cheating' orchids Corallorhiza maculata and C. mertensiana. Molecular Ecology 8: 1719-1732.

Taylor, D. L., T. D. Bruns, J. R. Leake, And D. J. Read. 2002. Mycorrhizal specificity and function in myco-heterotrophic plants. In M. G. A. van der Heijden and I. Sanders [eds.], Mycorrhizal ecology. Ecological studies vol. 157, 375-413. Springer-Verlag, Berlin, Germany.

Taylor, D. L., T. D. Bruns, T. M. Szaro, and S. A. Hodges. 2003. Divergence in mycorrhizal specialization within Hexalectris spicata (Orchidaceae), a nonphotosynthetic desert orchid. American Journal of Botany 90: 1168-1179.

TAYLOR, D. L., AND M. K. MCCORMICK. 2008. Internal transcribed spacer primers and sequences for improved characterization of basidiomycetous orchid mycorrhizas. New Phytologist 177: 1020-1033.

Thompson, J. N. 1986. Patterns in coevolution. In A. R. Stone and D. J. Hawksworth [eds.], Coevolution and systematics, 119-143. Clarendon Press, Oxford, UK.

Thompson, J. N. 1994. The coevolutionary process. University of Chicago Press, Chigaco, Illinois, USA. 
Tremblay, R. L., And J. D. Ackerman. 2001. Gene flow and effective population size in Lepanthes (Orchidaceae): A case for genetic drift. Biological Journal of the Linnean Society 72: 47-62.

WARCuP, J. H. 1981. The mycorrhizal relationships of Australian orchids. New Phytologist 87: 371-381.

WarCUP, J. H. 1990. Mycorrhizas In R. J. Bates and J. Z. Weber [eds.], Orchids of South Australia, 21-26. Orchids of South Australia, Flora and Fauna of South Australia Handbook Committee, Adelaide, Australia.

Waterman, R. J., AND M. I. Bidartondo. 2008. Deception above, deception below: Linking pollination and mycorrhizal biology of orchids. Journal of Experimental Botany 59: 1085-1096.
Weiblen, G. D. 2004. Correlated evolution in fig pollination. Systematic Biology 53: 128-139.

WheELER, Q. D. 2005. Losing the plot: DNA "barcodes" and taxonomy. Cladistics 21: 405-407.

White, T. J., T. Bruns, S. Lee, and J. W. Taylor. 1990. Amplification and direct sequencing of fungal ribosomal RNA genes for phylogenetics. In M. A. Innis, D. H. Gelfand, J. J. Sninsky, and T. J. White [eds.], PCR protocols: A guide to methods and applications, 315-322. Academic Press, San Diego, California, USA.

Will, K. W., B. D. Mishler, AND Q. D. WheELer. 2005. The perils of DNA barcoding and the need for integrative taxonomy. Systematic Biology 54: 844-851.

APPENDIX 1. Voucher information for the present study. Culture collections are located in the author's laboratory at the Australian National University, Canberra (ANU).

Taxon; Host; GenBank accessions: ITS; mtLSU; Voucher specimen; Collection site.

Tulasnella sp.; Chiloglottis aff. jeanesii; HM196792; HM196774; 06082.I.1.1; Tallaganda State Forest, NSW, Australia. Tulasnella sp.; Chiloglottis aff. jeanesii; HM196791; -; 06082.I.1.2; Tallaganda State Forest, NSW, Australia. Tulasnella sp.; Chiloglottis aff. jeanesii; HM196791; —; 06082.I.1.3; Tallaganda State Forest, NSW, Australia. Tulasnella sp.; Chiloglottis aff. jeanesii; HM196812; HM196774; 06082.I.3; Tallaganda State Forest, NSW, Australia. Tulasnella sp.; Chiloglottis aff. jeanesii; HM196779; HM196773; CP0835.I.1.1; Kanangra Boyd National Park, NSW, Australia. Tulasnella sp.; Chiloglottis aff. jeanesii; HM196782; -; CP0835.I.1.2; Kanangra Boyd National Park, NSW, Australia. Tulasnella sp.; Chiloglottis aff. jeanesii; HM196782; CP0835.I.1.3; Kanangra Boyd National Park, NSW, Australia. Tulasnella sp.; Chiloglottis aff. jeanesii; —; HM196773; CP0835.I.2; Kanangra Boyd National Park, NSW, Australia. Tulasnella sp.; Chiloglottis aff. jeanesii; HM196779; HM196773; CP0835.III.1.1; Kanangra Boyd National Park, NSW, Australia. Tulasnella sp.; Chiloglottis aff. jeanesii; HM196788; HM196773; CP0835.III.1.3; Kanangra Boyd National Park, NSW, Australia. Tulasnella sp.; Chiloglottis aff. jeanesii; -; HM196773 CP0835.III.2; Kanangra Boyd National Park, NSW, Australia. Tulasnella sp.; Chiloglottis aff. jeanesii; HM196787; HM196774; CP0835. VIII.2.1; Kanangra Boyd National Park, NSW, Australia. Tulasnella sp.; Chiloglottis aff. jeanesii; HM196786; —; CP0835.VIII.2.2; Kanangra Boyd National Park, NSW, Australia. Tulasnella sp.; Chiloglottis aff jeanesii; HM196783; —; CP0835.VIII.2.3; Kanangra Boyd National Park, NSW, Australia. Tulasnella sp.; Chiloglottis aff. jeanesii; HM196795; HM196773; CP0835.IX.1.3; Kanangra Boyd National Park, NSW, Australia. Tulasnella sp.; Chiloglottis aff. jeanesii; HM196785, HM196773; CP0835.IX.2.1; Kanangra Boyd National Park, NSW, Australia. Tulasnella sp.; Chiloglottis aff. jeanesii; HM196786; CP0835.IX.2.2; Kanangra Boyd National Park, NSW, Australia. Tulasnella sp.; Chiloglottis aff. jeanesii; HM196782; —; CP0835.IX.2.3; Kanangra Boyd National Park, NSW, Australia. Tulasnella sp.; Chiloglottis aff. jeanesii; HM196781; HM196773; CP0835.IX.3.2; Kanangra Boyd National Park, NSW, Australia. Tulasnella sp.; Chiloglottis aff. jeanesii; HM196780; —; CP0835.IX.3.3; Kanangra Boyd National Park, NSW, Australia. Tulasnella sp.; Chiloglottis valida D.L.Jones; HM196801; HM196773; CV0836.I.1; Kanangra Boyd National Park, NSW, Australia. Tulasnella sp.; Chiloglottis valida D.L.Jones; —; HM196773; CV0836. II.1; Kanangra Boyd National Park, NSW, Australia. Tulasnella sp.; Chiloglottis valida D.L.Jones; HM196804; HM196774; CV0627.II.1; Tallaganda State Forest, NSW, Australia. Tulasnella sp.; Chiloglottis valida D.L.Jones; -; HM196774; CV0627.II.2; Tallaganda State Forest, NSW, Australia. Tulasnella sp.; Chiloglottis diphylla R.Br.; HM196774; 505.III.1; Blue Mountains-Bells Line Rd, NSW, Australia. Tulasnella sp.; Chiloglottis diphylla R.Br.; HM196803; HM196774; 505. III.5; Blue Mountains-Bells Line Rd, NSW, Australia. Tulasnella sp.; Chiloglottis diphylla R.Br.; —; HM196774; 07054.I.1; Blue MountainsBells Line Rd, NSW, Australia. Tulasnella sp.; Chiloglottis diphylla R.Br.; —; HM196772; 07054.II.1; Blue Mountains-Bells Line Rd, NSW, Australia. Tulasnella sp.; Chiloglottis diphylla R.Br.; -; HM196774; 07054.VI.1; Blue Mountains-Bells Line Rd, NSW, Australia. Tulasnella sp.; Chiloglottis diphylla R.Br.; HM196802; HM196772; 07050.I.1; Blue Mountains-Bells Line Rd, NSW, Australia. Tulasnella sp.; Chiloglottis diphylla R.Br.; -; HM196774; 07048.I.1; Blue Mountains-Bells Line Rd, NSW, Australia. Tulasnella sp.; Chiloglottis diphylla R.Br.; —; HM196774; 07053.III.1; Blue Mountains-Bells Line Rd, NSW, Australia. Tulasnella sp.; Chiloglottis reflexa (Labill.) Druce; HM196805; HM196774; 07061.I.1; Mt Wilson, Blue Mountains, NSW, Australia. Tulasnella sp.; Chiloglottis reflexa (Labill.) Druce; -; HM196774; 07061.I.7; Mt Wilson, Blue Mountains, NSW, Australia. Tulasnella sp.; Chiloglottis reflexa (Labill.) Druce; -; HM196774; 07061.III.7; Mt Wilson, Blue Mountains, NSW, Australia. Tulasnella sp.; Chiloglottis reflexa (Labill.) Druce; —; HM196774; 07071.I.1; Mt Wilson, Blue Mountains, NSW, Australia. Tulasnella sp.; Chiloglottis reflexa (Labill.) Druce; —; HM196774; 07072.II.3; Mt Wilson, Blue Mountains, NSW, Australia. Tulasnella sp.; Chiloglottis reflexa (Labill.) Druce; HM196774; 07072.II.4; Mt Wilson, Blue Mountains, NSW, Australia. Tulasnella sp.; Chiloglottis seminuda D.L.Jones; -; HM196774; 07033.I.1; Penrose Forest, Exeter, NSW, Australia. Tulasnella sp. Chiloglottis seminuda D.L.Jones; -; HM196774; 07033.I.2; Penrose Forest, Exeter, NSW, Australia. Tulasnella sp.; Chiloglottis seminuda D.L.Jones; - ; HM196774; 07033.II.1; Penrose Forest, Exeter, NSW, Australia. Tulasnella sp.; Chiloglottis seminuda D.L.Jones; HM196798; HM196774; 07033.II.2.1; Penrose Forest, Exeter, NSW, Australia. Tulasnella sp.; Chiloglottis seminuda D.L.Jones; HM196797; —; 07033.II.2.2; Penrose Forest, Exeter, NSW, Australia. Tulasnella sp.; Chiloglottis seminuda D.L.Jones; -; HM196774; 07033.II.3; Penrose Forest, Exeter, NSW, Australia. Tulasnella sp.; Chiloglottis seminuda D.L.Jones; -; HM196774; 07033.III.1; Penrose Forest, Exeter, NSW, Australia. Tulasnella sp.; Chiloglottis seminuda D.L.Jones; HM196800; HM196774; 07033-45.I.2; Penrose Forest, Exeter, NSW, Australia. Tulasnella sp.; Chiloglottis seminuda D.L.Jones; —; HM196774; 07033. IV.1; Penrose Forest, Exeter, NSW, Australia. Tulasnella sp.; Chiloglottis seminuda D.L.Jones; —; HM196774; 07033.IV.2; Penrose Forest, Exeter, NSW, Australia. Tulasnella sp.; Chiloglottis trapeziformis Fitzg.; -; HM196774; CM07.I.2; Black Mountain, ACT, Australia. Tulasnella sp.; Chiloglottis trapeziformis Fitzg.; HM196794; HM196774 CM07.I.5; Black Mountain, ACT, Australia. Tulasnella sp.; Chiloglottis trapeziformis Fitzg.; —; HM196774; CM07.I.9; Black Mountain, ACT, Australia. Tulasnella sp.; Chiloglottis trapeziformis Fitzg.; HM196799; HM196774; CM07.I.10; Black Mountain, ACT, Australia. Tulasnella sp.; Chiloglottis trapeziformis Fitzg.; HM196789; HM196774; CM07. II.1.1; Black Mountain, ACT, Australia. Tulasnella sp.; Chiloglottis trapeziformis Fitzg.; HM196789; _; CM07.II.1.2; Black Mountain, ACT, Australia. Tulasnella sp.; Chiloglottis trapeziformis Fitzg.; HM196789; _; CM07.II.1.3; ANBG, Black Mountain, ACT, Australia. Tulasnella sp.; Chiloglottis trapeziformis Fitzg.; -; HM196774; SRBG01.I.1; ANBG, Black Mountain, ACT, Australia. Tulasnella sp.; Chiloglottis trapeziformis Fitzg.; HM196796; HM196774; SRBG01.II.1; ANBG, Black Mountain, ACT, Australia. Tulasnella sp.; Chiloglottis trapeziformis Fitzg.; —; HM196774; SRBG01.II.2; ANBG, Black Mountain, ACT, Australia. Tulasnella sp.; Chiloglottis trapeziformis Fitzg.; HM196793; 
HM196774; SRBG01.II.3.1; ANBG, Black Mountain, ACT, Australia. Tulasnella sp.; Chiloglottis trapeziformis Fitzg.; HM196790; —; SRBG01.II.3.2; ANBG, Black Mountain, ACT, Australia. Tulasnella sp.; Chiloglottis trapeziformis Fitzg.; —; HM196774; SRBG01.II.4; ANBG, Black Mountain, ACT, Australia.

Uncultured Tulasnella sp.; Chiloglottis trapeziformis Fitzg.; HM196809; —; SRBM01.I.3.1; ANBG, Black Mountain, ACT, Australia. Uncultured Tulasnella sp.; Chiloglottis trapeziformis Fitzg.; HM196813; -; SRBM01.I.3.2; ANBG, Black Mountain, ACT, Australia. Uncultured Tulasnellasp.; ChiloglottistrapeziformisFitzg.;HM196810;-;SRBG03.I.3; ANBG, Black Mountain, ACT, Australia. Uncultured Tulasnella sp.; Chiloglottis trapeziformis Fitzg.; HM196811; —; SRBG03.I.6; ANBG, Black Mountain, ACT, Australia. Uncultured Tulasnella sp.; Chiloglottis trapeziformis Fitzg.; HM196807; —; SRBG03.I.7; ANBG, Black Mountain, ACT, Australia. Uncultured Tulasnella sp.; Chiloglottis trapeziformis Fitzg.; HM196807; —; SRBG03.I.8; ANBG, Black Mountain, ACT, Australia. Uncultured Tulasnella sp.; Chiloglottis trapeziformis Fitzg.; HM196808; —; SRBG03.II.1; ANBG, Black Mountain, ACT, Australia.

Uncultured endophytic fungus; Chiloglottis trapeziformis Fitzg.; HM196778; —; SRBG03.II.2; ANBG, Black Mountain, ACT, Australia. Uncultured endophytic fungus; Chiloglottis trapeziformis Fitzg.; HM196778; —; SRBG03.II.3; ANBG, Black Mountain, ACT, Australia. Uncultured Tulasnella sp.; Chiloglottis trapeziformis Fitzg.; HM196813; —; SRBG03. III.1; ANBG, Black Mountain, ACT, Australia. Uncultured endophytic fungus; Chiloglottis trapeziformis Fitzg.; HM196778; -; SRBG03. III.2; ANBG, Black Mountain, ACT, Australia. Uncultured endophytic fungus; Chiloglottis trapeziformis Fitzg.; HM196778; -; SRBG03. III.3; ANBG, Black Mountain, ACT, Australia. Uncultured endophytic fungus; Chiloglottis trapeziformis Fitzg.; HM196775; —; SRBG03. III.5; ANBG, Black Mountain, ACT, Australia. Uncultured endophytic fungus; Chiloglottis trapeziformis Fitzg.; HM196775; —; SRBG03.III.6; ANBG, Black Mountain, ACT, Australia. Uncultured endophytic fungus; Chiloglottis trapeziformis Fitzg.; HM196777; —; SRBG03.III.11; ANBG, Black Mountain, ACT, Australia. Uncultured Tulasnella sp.; Chiloglottis trapeziformis Fitzg.; HM196810; 一; SRBG03.III.12; ANBG, Black Mountain, ACT, Australia. Uncultured endophytic fungus; Chiloglottis trapeziformis Fitzg.; HM196776; —; SRBG03.III.13; ANBG, Black Mountain, ACT, Australia. Uncultured endophytic fungus; Chiloglottis trapeziformis Fitzg.;HM196777;-_;SRBG03.IV.1;ANBG,Black Mountain, ACT, Australia. Uncultured endophytic fungus; Chiloglottis trapeziformis Fitzg.; HM196778; —; SRBG03.IV.2; ANBG, Black Mountain, ACT, Australia. Uncultured endophytic fungus; Chiloglottis trapeziformis Fitzg.; HM196778; —; SRBG03.IV.3; ANBG, Black Mountain, ACT, Australia. Uncultured Tulasnella sp.; Chiloglottis trapeziformis Fitzg.; HM196813; —; SRBG03.IV.4; ANBG, Black Mountain, ACT, Australia Uncultured Tulasnella sp.; Chiloglottis trapeziformis Fitzg.; HM196806; —; SRBG03.IV.5; ANBG, Black Mountain, ACT, Australia. Uncultured Tulasnella sp.; Chiloglottis trapeziformis Fitzg.; HM196813; —; SRBG03. IV.6; ANBG, Black Mountain, ACT, Australia. 